\title{
Handedness in twins: meta-analyses
}

\author{
Lena Sophie Pfeifer ${ }^{1 * \dagger}$, Judith Schmitz ${ }^{2 \dagger}$, Marietta Papadatou-Pastou ${ }^{3,4}$, Jutta Peterburs ${ }^{5}$, Silvia Paracchini ${ }^{2}$ and
} Sebastian Ocklenburg ${ }^{6}$

\begin{abstract}
Background: In the general population, $10.6 \%$ of people favor their left hand over the right for motor tasks. Previous research suggests higher prevalence of atypical (left-, mixed-, or non-right-) handedness in (i) twins compared to singletons, and in (ii) monozygotic compared to dizygotic twins. Moreover, (iii) studies have shown a higher rate of handedness concordance in monozygotic compared to dizygotic twins, in line with genetic factors playing a role for handedness.
\end{abstract}

Methods: By means of a systematic review, we identified 59 studies from previous literature and performed three sets of random effects meta-analyses on (i) twin-to-singleton Odds Ratios (21 studies, $n=189,422$ individuals) and (ii) monozygotic-to-dizygotic twin Odds Ratios (48 studies, $n=63,295$ individuals), both times for prevalence of left-, mixed-, and non-right-handedness. For monozygotic and dizygotic twin pairs we compared (iii) handedness concordance Odds Ratios (44 studies, $n=36,217$ twin pairs). We also tested for potential effects of moderating variables, such as sex, age, the method used to assess handedness, and the twins'zygosity.

Results: We found (i) evidence for higher prevalence of left- (Odds Ratio $=1.40,95 \%$ Confidence Interval $=[1.26$, 1.57]) and non-right- (Odds Ratio $=1.36,95 \%$ Confidence Interval $=[1.22,1.52]$ ), but not mixed-handedness (Odds Ratio $=1.08,95 \%$ Confidence Interval $=[0.52,2.27]$ ) among twins compared to singletons. We further showed a decrease in Odds Ratios in more recent studies (post-1975: Odds Ratio $=1.30,95 \%$ Confidence Interval $=[1.17,1.45]$ ) compared to earlier studies (pre-1975: Odds Ratio $=1.90,95 \%$ Confidence Interval $=[1.59-2.27]$ ). While there was (ii) no difference between monozygotic and dizygotic twins regarding prevalence of left- (Odds Ratio $=0.98$, 95\% Confidence Interval $=[0.89,1.07])$, mixed- (Odds Ratio $=0.96,95 \%$ Confidence Interval $=[0.46,1.99])$, or non-right-handedness (Odds Ratio $=1.01,95 \%$ Confidence Interval $=[0.91,1.12]$ ), we found that (iii) handedness concordance was elevated among monozygotic compared to dizygotic twin pairs (Odds Ratio $=1.11,95 \%$ Confidence Interval $=[1.06$, 1.18]). By means of moderator analyses, we did not find evidence for effects of potentially confounding variables.

Conclusion: We provide the largest and most comprehensive meta-analysis on handedness in twins. Although a raw, unadjusted analysis found a higher prevalence of left- and non-right-, but not mixed-handedness among twins compared to singletons, left-handedness was substantially more prevalent in earlier than in more recent studies. The single large, recent study which included birth weight, Apgar score and gestational age as covariates found no twin-singleton difference in handedness rate, but these covariates could not be included in the present meta-analysis. Together, the secular shift and the influence of covariates probably make it unsafe to conclude that twinning has a genuine relationship to handedness.

\footnotetext{
*Correspondence: Lena.Pfeifer@rub.de

${ }^{\dagger}$ Lena Sophie Pfeifer and Judith Schmitz: shared first-authorship

${ }^{1}$ Cognitive Psychology, Institute of Cognitive Neuroscience, Faculty

of Psychology, Ruhr University Bochum, Universitätsstraße 150,

44780 Bochum, Germany

Full list of author information is available at the end of the article
}

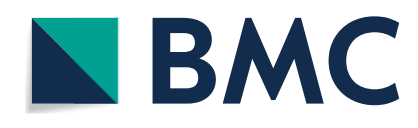

(c) The Author(s) 2022. Open Access This article is licensed under a Creative Commons Attribution 4.0 International License, which permits use, sharing, adaptation, distribution and reproduction in any medium or format, as long as you give appropriate credit to the original author(s) and the source, provide a link to the Creative Commons licence, and indicate if changes were made. The images or other third party material in this article are included in the article's Creative Commons licence, unless indicated otherwise in a credit line to the material. If material is not included in the article's Creative Commons licence and your intended use is not permitted by statutory regulation or exceeds the permitted use, you will need to obtain permission directly from the copyright holder. To view a copy of this licence, visit http://creativecommons.org/licenses/by/4.0/. The Creative Commons Public Domain Dedication waiver (http://creativeco $\mathrm{mmons}$.org/publicdomain/zero/1.0/) applies to the data made available in this article, unless otherwise stated in a credit line to the data. 
Keywords: Handedness, Twins, Meta-analysis, Laterality, Hemispheric asymmetry

\section{Introduction}

Handedness is a form of human motor lateralization which has been studied extensively [1] as it is commonly understood as a proxy for functional brain lateralization [2]. Handedness shows a robust population-level asymmetry, with the great majority of people being righthanded and only $10.6 \%$ being left-handed as estimated by a recent meta-analysis [3].

However, left-handedness prevalence seems to vary in different populations. For example, it is well established that left-handedness occurs more often among males as compared to females [4]. Similarly, higher prevalence of atypical handedness has been reported in twins [5-9]. This finding was confirmed by Sicotte et al. [10] using meta-analysis. Without investigating moderators, the authors hypothesized that this effect could be mediated by pre- or perinatal circumstances which are more prevalent in twins or other form of multiples as compared to singletons [11-13]. For example, elevated proportions of left-handers were observed among singletons who experienced birth stress [14-16] and among children who were born preterm [17], by Caesarian section [18, 19], or struggled with breathing during birth [20]. Another aspect frequently associated with a tendency towards non-right-handedness is lower birth weight [21-23]. In a sample of Japanese and Dutch triplets, Heikkilä et al. [24] confirmed that left-handers displayed significantly lower birth weight than right-handers. In a recent largescale study using the UK Biobank $(n \sim 500,000)$, small but significant effects of birth year (increase in righthandedness of $0.7 \%$ per decade), birth weight (on average, right-handers are $\sim 26 \mathrm{~g}$ heavier) as well as being part of a multiple birth (singletons $=9.5 \%$ left-handedness, multiples $=11.2 \%$ left-handedness, OR for right-handedness $=0.83$ ) on handedness have been confirmed [25].

Sicotte et al. [10] also tested for differences in the prevalence of left-handedness between and monozygotic (MZ) and dizygotic (DZ) twins but found no effect.

As MZ twins share $100 \%$ of their DNA while DZ twins overlap on only $50 \%$ of genetic variants $[2,26]$, the twin model is often used to estimate heritability of one phenotypic trait [27]. A higher handedness concordance among MZ twins as compared to DZ twins [28-30] indicates a significant role of genetic factors in the ontogenesis of handedness. This was also confirmed by Sicotte et al. [10] (mean OR across studies $=1.37$ ). Handedness heritability was estimated to be $0.24-0.26$ in large samples of 21,127 twin pairs [31] or samples consisting of twins and their siblings adding up to 54,270 individuals [32]. Similarly,
Somers et al. [33] estimated the heritability of left-handedness to be around 0.24 from a genetic linkage study in human pedigrees. In a large GWAS, Cuellar-Partida et al. [34] reported single nucleotide polymorphism (SNP) based heritability estimates of $5.9 \%$ for left-handedness and $12 \%$ for ambidexterity. This indicates that genetic factors account for up to one quarter of the variability of handedness.

Recently, several studies have been published on twin handedness. However, findings are not always in agreement, with different studies giving different estimates. For example, Zheng et al. [35] or Medland et al. [36] did not replicate a higher prevalence of atypical handedness in twins. Meta-analytic approaches can quantitively summarize the literature to provide an overall reliable estimate of handedness differences. Moreover, they can investigate possible small study bias in the literature and importantly allow for moderator analyses to investigate variables that could moderate the prevalence of handedness categories among twins [37]. Indeed, the vast field of handedness has recently seen an upsurge of metaanalyses that aim to summarize the literature and provide estimates of atypical handedness in various populations (e.g., individuals with autism [38], deaf individuals [39], intellectually disabled and intellectually gifted individuals [40], individuals with ADHD [41]).

Sicotte et al. [10] do report a meta-analysis of the handedness literature in twins. However, their meta-analysis was published more than 20 years ago, calling for an update as numerous new data sets have been published over the course of more than two decades. As an illustration, using the search term "handedness twins" on PubMed for publications that have been published after 1999 yields 120 hits. While not all of these studies might be eligible for meta-analysis, this number points towards a substantial increase in empirical studies over that period. Including this more recent data in meta-analysis is important, not only because it might result in more reliable estimates but also because antiquated efforts of forcing left-handers to use their right hand have largely been terminated [32, 42-44]. Moreover, the Sicotte et al. [10] analysis is limited by the fact that it only considered leftand right-handers. However, there is a certain proportion of people that cannot be classified in either of these categories. The definition of this mid-category is rather unsharp and its labelling varies from "mixed-handedness" over "both-handedness" to "ambidexterity". As emphasized by Papadatou-Pastou et al. [3], even if these terms are often used interchangeably, "ambidextrous" 
refers to individuals being equally skilled with both hands while "mixed-handed" refers to individuals preferring to use different hands for different tasks. When handedness is determined as self-report of writing hand, it is thus by definition only possible to account for ambidexterity, but not mixed-handedness. In contrast, self-report questionnaires like the Edinburgh Handedness Inventory [45] assess the preferred hand for several manual activities, which therefore captures ambidextrous as well as mixedhanded individuals in the mid-category. Consequently, the meta-analysis by Papadatou-Pastou et al. [3] confirmed that the method to determine handedness affects precise point estimates of atypical handedness prevalence. The authors further found that the prevalence of this mid-category is $9.3 \%$, suggesting that a strong lateralization towards the right side is the common rule, whereas non-right-handedness (including left-, mixedhandedness and ambidexterity) is generally referred to as "atypical" handedness [3]. All in all, newly gathered insights may be capable of challenging the interpretations made by Sicotte et al. [10], and recent accumulations in overall data might even allow for divergent results.

Thus, the major goal of the present meta-analysis is to update the state of the art concerning the questions of whether atypical handedness occurs more often in twins than in singletons. Three sets of meta-analyses were conducted. Firstly, we compared the prevalence of atypical handedness in twins and singletons. Secondly, we examined whether atypical handedness occurs more often in MZ compared to DZ twins. Thirdly, we analyzed data on handedness in twins in a pairwise manner to test whether $M Z$ and $D Z$ twin pairs differ in their prevalence of handedness concordance. Beyond those three sets of meta-analyses, we performed various moderator analyses to elucidate whether additional factors such as inclusion in the Sicotte et al. [10] meta-analysis, method of determining zygosity, sex, age, year of publication, measurement of handedness, handedness classification, nature of the singleton group, and purpose of the study moderated potential differences in atypical handedness prevalence in twins and singletons.

\section{Materials and methods}

\section{Selection of studies for the meta-analyses}

The study selection by means of a systematic review as well as the conduction of all meta-analyses in this study followed the official PRISMA guidelines [46, 47]. As it is the aim of the PRISMA guidelines to increase the traceability of reviews and meta-analyses, it includes a concrete 27-item checklist which we applied for the selection and inclusion of studies in our meta-analyses (Additional file 2). Risk-of bias (also called critical appraisal) analysis was not deemed necessary for our included studies, because they were not assessing an intervention (therefore elements like blinding participants and randomization were not relevant) or an experimental manipulation (therefore elements like blinding of the experimenters were not relevant). Moreover, we only included published studies that may be assumed to have sufficient quality as a result of peer-review processes. However, we did check for various methodological qualities of our included studies, such as measurement of handedness, purpose of the study or way to determine zygosity in the context of several moderator analyses (see below).

The purpose of this study was to review and reanalyze the meta-analysis by Sicotte et al. [10] as well as to seek and aggregate new data on handedness in twins to update the state of the art. Therefore, we opted to combine the data of studies included in the meta-analysis by Sicotte et al. [10] with new data from recent studies which were identified in the course of an extensive literature search. If studies were not accessible online, local databases were searched for the respective articles or corresponding authors were contacted via e-mail requests when possible. Data collection as well as extraction was conducted by LP and concluded in September 2020. Details of this process are shown in Fig. 1. Data collection and extraction were evaluated by $\mathrm{SO}$ and discrepancies were resolved by discussion.

\section{Inclusion and exclusion criteria}

The following inclusion and exclusion criteria were applied:

1. Data: Studies needed to provide data on handedness in twins. For inclusion, studies either needed to allow (a) for a calculation of Odds Ratios (ORs) for a comparison of handedness between twins and singletons, (b) for a calculation of ORs for a comparison of handedness between MZ and DZ twins, or (c) for a calculation of ORs for a comparison of handedness concordance between MZ and DZ twins. In cases where studies reported arithmetic data in a way that did not allow for the calculation of ORs used in the meta-analyses (e.g., laterality indices, averages, quotients), we contacted the authors to ask for more specific information on the distribution of handedness groups across the sample. Studies were excluded if the authors did not provide that additional information.

2. Language: Studies had to be written in English to be included in our meta-analyses. Exceptions were made for the studies published in German or French which were included in the analysis by Sicotte et al. [10]. Concerning the German studies, we extracted the data ourselves, whereas for studies written in 


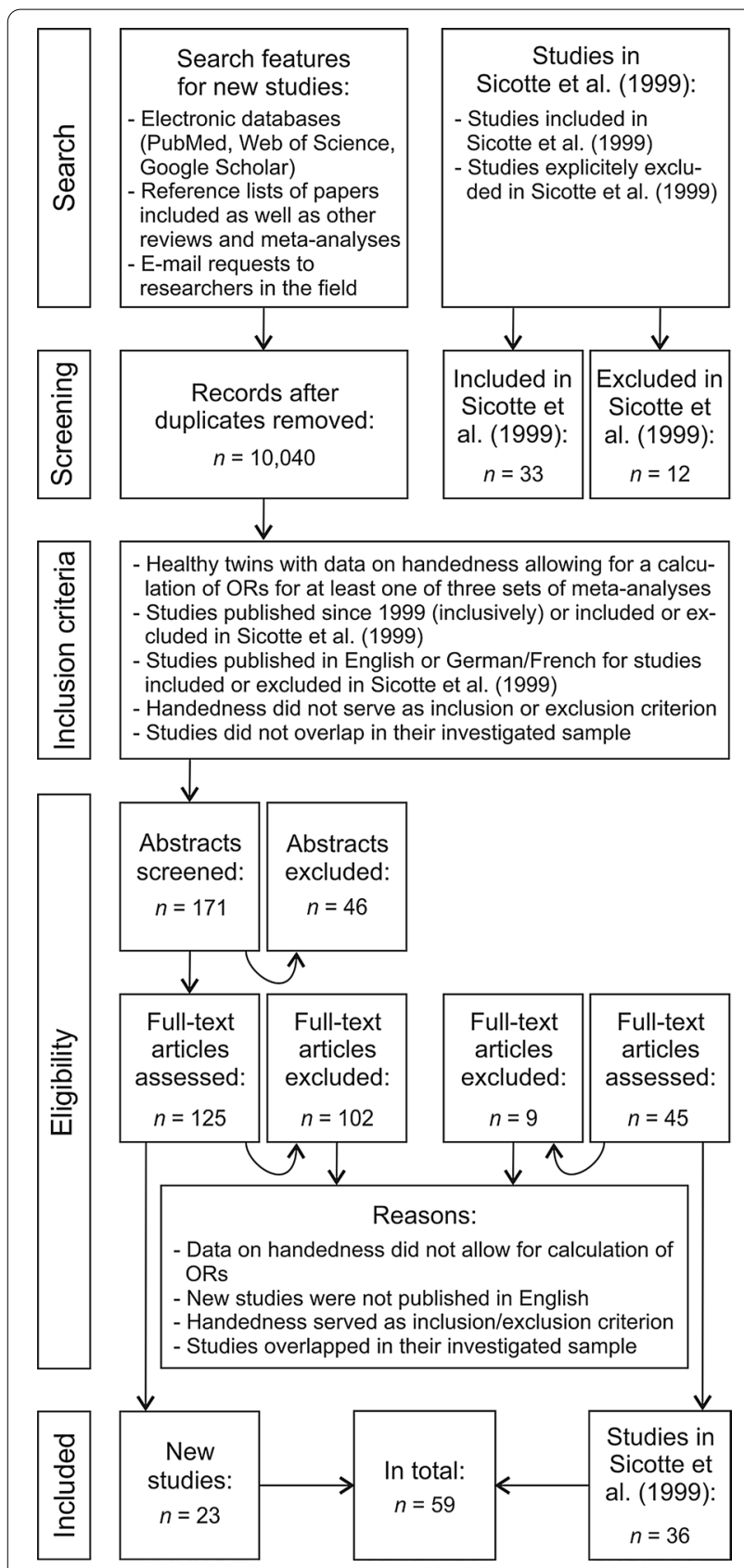

Fig. 1 Flow diagram depicting criteria from the PRISMA guidelines for systematic reviews and meta-analyses as well as inclusion and exclusion criteria which were applied in the course of search and inclusion of studies for these meta-analyses. Additional file 1: Table S1 contains a comprehensive list of all studies included in our meta-analyses

French we relied on the data extraction performed by Sicotte et al. [10].

3. Handedness: As it was our goal to investigate the prevalence of atypical handedness in twins, we excluded studies in which handedness was defined as an inclusion or exclusion criterion (e.g., left-handedness as exclusion criterion, participants matched for or selected on the basis of handedness or concordance/discordance for handedness).

4. Participants: As atypical handedness patterns are associated with several psychiatric [48-50] and neurodevelopmental [38] conditions, studies needed to provide data on handedness for healthy twins. In cases where mixed samples were examined [51-58], we only extracted data on handedness for twin pairs concordantly healthy who served as control twins in these studies. Therefore, the report of handedness data had to be precise enough to clearly distinguish between healthy control twins and affected twins (in cases where twins were discordant for conditions, we opted to also exclude the healthy co-twin). Likewise, when studies compared the handedness of twins and other multiples with sib-pairs or singletons, handedness had to be reported separately for those groups. For studies which did not report the data precisely enough for the mentioned groups, we contacted the authors to ask for additional information. Studies were excluded if the authors did not provide this information. In total, we included 59 studies (including 32 studies already included in Sicotte et al. [10]) in our meta-analyses (Fig. 1). A comprehensive list of all included studies is presented in Additional files 1, 2. Studies included in the meta-analyses are marked with asterisks in the reference list.

\section{Studies included in the meta-analysis by Sicotte et al. (1999)}

We aimed to include the studies analyzed by Sicotte et al. [10] but screened them against our inclusion and exclusion criteria (see above) as those slightly deviated from the ones applied by Sicotte et al. [10]. In detail, these authors included all studies containing at least ten twin pairs and providing data on two or more groups of individuals. As a result, we excluded one study [7] because it seemed to contain other forms of multiples apart from twins (e.g., triplets) and reported data on handedness in a combined manner for them. Furthermore, we checked twelve studies which were explicitly reported to have been excluded in the meta-analysis by Sicotte et al. [10]. We opted to include four of these because they fulfilled our inclusion criteria. In detail, Sicotte et al. [10] excluded these studies due to incorrect references [59] or the lack of pair-wise data $[60,61]$. In contrast, we were able to use these studies for at least one of our comparisons. Moreover, Sicotte et al. [10] excluded two studies $[60,62]$ as the exact number of twins was not stated. As we were able to calculate the number, we could include 
both studies. Overall, we analyzed 32 studies included in the meta-analysis by Sicotte et al. [10] and four studies explicitly excluded by Sicotte et al. [10] providing data on handedness in twins covering publications from 1924 to 1996.

\section{New studies}

New data were collected by means of literature search for all studies that reported handedness for twins (regardless of whether it was the original purpose of the study to examine handedness or not) and that had been published since 1999 (inclusively). Thereby, we tried to ensure including all studies not covered by Sicotte et al. [10] as they reported having conducted their search for studies from 1966 to "present" so that we assumed their latest results to cover the years 1998/1999. In detail, the electronic databases PubMed (https://www.ncbi.nlm. nih.gov/pubmed/), Web of Science (https://www.webof knowledge.com), and Google Scholar (https://scholar. google.de/) were searched for the terms "handedness" AND "twins", "hand preference" AND "twins", "hand skill" AND "twins" and "twins" AND "pegboard". By means of these search terms, we further extended the work by Sicotte et al. [10] who restricted their literature review to the keywords "twins" and "handedness". Reference lists of included papers as well as other reviews and meta-analyses were further used as source to identify further studies $[2,31,36,63,64]$. This is in line with the search by Sicotte et al. [10] who similarly included studies that were identified in prior reviews.

\section{Overlapping datasets}

In cases where the same data were used by more than one study, the dataset was included in our analyses only once. We checked overlapping studies separately for the three sets of meta-analyses we performed, as it was conceivable that the same dataset was depicted in different ways by different studies so that one publication might have allowed extraction of the data for our first set of metaanalyses while another publication on the same sample might have allowed extraction of the data for the second set of meta-analyses.

First, the twins included in Segal [65] and Gopalakrishman [66] seemed to overlap with the twins investigated by Sicotte et al. [10], so we could not include those new studies.

For new studies overlapping in their investigated datasets, we opted to include the oldest study, with the exception when a more recent study included a larger dataset. Specifically, Hulshoff Pol et al. [67] seemed to overlap with Bootsman [68] for the Netherlands Twin Registry. As Hulshoff Pol et al. [67] was older and included more data, we opted to include this study and to exclude Bootsman [68].

Similarly, Vuoksimaa et al. [69] seemed to overlap with several studies [70-76] for the Older Finnish Twin Cohort of same-sex twin pairs born in Finland before 1958. As Vuoksimaa et al. [69] provided the most data on this sample, we chose to include this study and to exclude all others. Heikkilä et al. [77] also seemed to report data on this sample by means of the FinnTwin 12 cohort. However, this study also included the FinnTwinn16 cohort, so we extracted data only for this dataset out of Heikkilä et al. [77]. Moreover, Heikkilä [78] overlapped with Heikkilä et al. [77]. The latter was a doctoral dissertation in which this study as well as two others (which we assessed and excluded in the process of our data collection for this meta-analysis) were included. Therefore, we opted to include Heikkilä et al. [77] and to exclude Heikkilä [78].

Moreover, several studies overlapped for Australian twin samples. Medland et al. [79] included two samples of which only the second one allowed for the second and the third set of meta-analyses. However, this sample was based on the Brisbane Adolescent Twin Study which was also described in Medland et al. [36]. As Medland et al. [36] was older and provided far more data, we opted to include this study to account for Australian twins. As a result, we also had to exclude Kanchibhotla et al. [80] as this study was based on the Australian Twin Registry which was already covered by Medland et al. [36] as well. As Dooland et al. [81] reported dental schools in Adelaide and Melbourne as their primary source of recruitment, this study did not overlap with Medland et al. [36] and was therefore included. Finally, data reported in Medland et al. [36] were extracted from Medland et al. [31] as they were reported in more detail in that article. Similarly, pairwise data had not been reported by Basso et al. [82] and were extracted from Medland et al. [31] who reported the pairwise data after having contacted the original authors.

\section{Data extraction}

We relied on the data extraction performed by Sicotte et al. [10] for five studies as they were either written in French [28, 83, 84], we had no access to it [85], or Sicotte et al. [10] reported far more data than we could find, assuming that they had received additional material by the original study authors [86].

For all other studies reported by Sicotte et al. [10], we extracted the data from the original papers. In cases where handedness data for individuals and pairs were conflicting (e.g., when not all individuals originated from complete pairs), we opted for the individual data. Nevertheless, in the context of our third set of meta-analyses, we acknowledged pairwise data but concentrated 
on handedness concordance or discordance of pairs not taking into account information on the specific handedness direction (e.g., for concordant pairs, we did not distinguish between R-R- (both twins right-handed), L-L(both twins left-handed), or A-A- (both twins mixedhanded/ambidextrous) pairs). Likewise, data extraction for our meta-analyses partly resulted in some deviations from the data reported by Sicotte et al. [10]. For instance, we extracted data on handedness categories as detailed as possible using mixed-handedness as its own handedness category. Sicotte et al. [10], in contrast, subsumed individuals reported to be ambidextrous in the original studies under left-handers, thus reducing detail by only distinguishing between right- and left-handedness.

\section{Statistical analysis}

All meta-analyses were performed in R using the metafor package [87]. To address our research questions, we performed the following three sets of meta-analyses:

Meta-analysis set 1: The first set of meta-analyses addressed the question of whether twins and singletons differ in their prevalence of atypical handedness (left-handedness, mixed-handedness, or non-righthandedness). This analysis was run on all studies that provided separate handedness data for twins and singletons (21 studies). Odds Ratios (ORs) were calculated for twins vs. singletons for left-, mixed-, and non-right-handedness. An OR of 1 is indicative of no group difference, while ORs $>1$ suggest a higher prevalence of atypical handedness in twins compared to singletons and ORs $<1$ suggest a higher prevalence of atypical handedness in singletons compared to twins. Random effects models were run on the ORs for left-, mixed-, and non-right-handedness, followed by a moderator variable analysis (see below).

The atypical handedness groups correspond to the following:

1. The left-handedness group included left-handers from the "right vs. left" (R-L), "right vs. ambidextrous/mixed-handed vs. left" (R-A-L), and "left vs. non-left" (L-NL) classifications (red box in Fig. 2).

2. The mixed-handedness group included mixed-handers in the R-A-L classification (blue box in Fig. 2). The nature of this group depends on the instrument used to assess handedness. For example, studies using a writing hand criterion (e.g. Vuoksimaa et al. [69]) identify ambidextrous individuals (who use both hands for writing), as their middle category, while studies using several hand preference items (e.g. Shimizu et al. [88]), also identify mixed-handed individuals (who use the left hand for some tasks

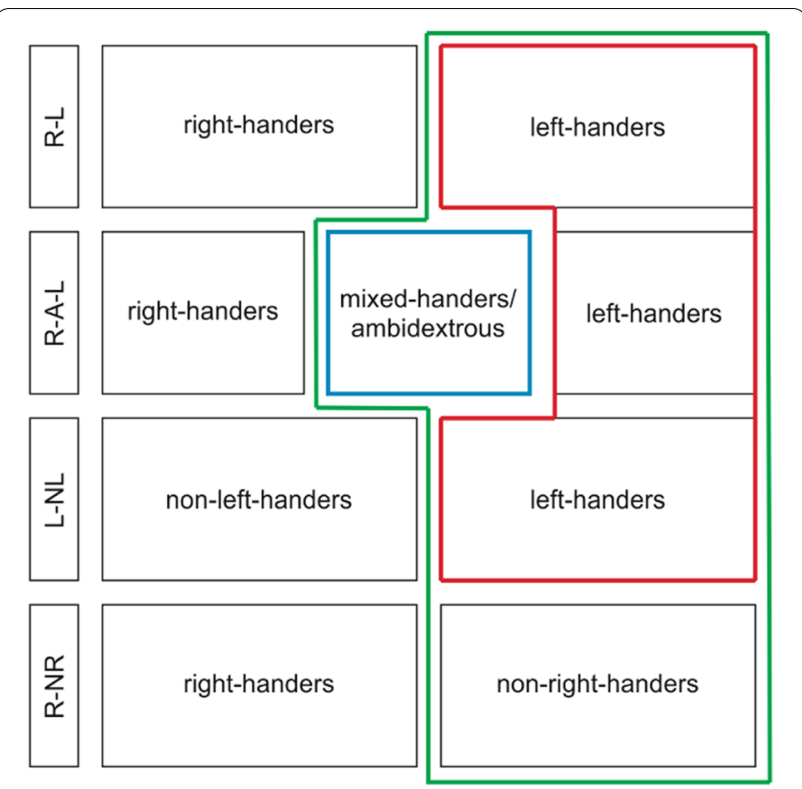

Fig. 2 Visualisation of the atypical handedness groups per classification. The red box represents groups included in the left-handedness comparison, the blue box represents the group included in the mixed-handedness comparison, and the green box represents groups included in the non-right-handedness comparison

and the right hand for other tasks). Here, we generally refer to the mid-category as it was defined by the original studies (individuals that were not assigned to the group of right-handers or left-handers) when referring to 'mixed-handedness'. Therefore, the mixed-handed group consists of both mixed-handers and ambidextrous individuals.

3. The non-right-handedness group included lefthanders (R-L and R-A-L), mixed-handers (R-A-L), and non-right-handers ("right vs. non-right", R-NR) (green box in Fig. 2).

Meta-analysis set 2: The second set of meta-analyses addressed the question of whether MZ and DZ twins differ in their prevalence of left-, mixed-, or nonright-handedness. This analysis was run on all studies that provided separate handedness data for MZ and DZ twins (48 studies). ORs were calculated for MZ vs. DZ twins for left-, mixed-, and non-right-handedness. ORs $>1$ suggest higher prevalence of atypical handedness in MZ twins compared to DZ twins, and ORs $<1$ suggest higher prevalence of atypical handedness in $\mathrm{DZ}$ twins compared to MZ twins. We ran random effects models on the ORs for left-, mixed-, and non-right-handedness, followed by a moderator variable analysis (see below). 
Meta-analysis set 3: The third set of meta-analyses addressed the question of whether MZ and DZ twin pairs differ in the prevalence of pairwise handedness concordance. This analysis was run on all studies that provided pairwise handedness data for $\mathrm{MZ}$ and $\mathrm{DZ}$ twins (44 studies). An OR was calculated for handedness concordance in MZ vs. DZ twins. An OR > 1 suggests higher concordance in $\mathrm{MZ}$ twins compared to $\mathrm{DZ}$ twins, and an $\mathrm{OR}<1$ suggests higher concordance in DZ twins compared to MZ twins. We ran a random effects model on concordance OR and subsequently ran a moderator variable analysis (see below).

\section{Study heterogeneity and small study bias}

For each meta-analysis, we tested for homogeneity using the $I^{2}$ index reflecting the variance explained by heterogeneity across studies. The $I^{2}$ index is assumed to be low, moderate, and high, when it takes values close to $25 \%, 50 \%$, and $75 \%$ respectively [89]. The $\mathrm{Tau}^{2}$ index was used to specify variance between studies. We visually inspected the funnel plot created using the funnel() function to identify small study bias. Funnel plot asymmetry was also assessed using Egger's regression test (regtest() function). Finally, the trim and fill method (trimfill() function) [90] was used to impute data points in order to make the funnel plot symmetrical.

\section{Moderator analyses and variables}

1. Sicotte et al. (1999) meta-analysis: In order to compare our results with those obtained by Sicotte et al. [10], we first tested for an effect of inclusion in the Sicotte et al. (1999) meta-analysis (included in Sicotte et al. [10], excluded from Sicotte et al. [10], new studies) on ORs. This analysis was run for all three sets of meta-analyses (1,2, and 3).

2. Year of publication: As it has been shown that early studies bias the distribution of handedness categories [3], we tested for any moderating effects of the year of publication of the original study on ORs in the twins vs. singletons meta-analysis (meta-analysis set 1 ).

3. Ancestry: As handedness is believed to be partially genetically determined, we investigated moderating effects of ancestry in terms of the genetical origin of the participants of the original studies. In this context we distinguished between (a) Europe/ USA/Australia and (b) East Asia. This analysis was run for the twins vs. singletons meta-analysis (meta-analysis set 1 ).
4. Purpose of the study: We investigated if there was any moderating effect of whether (a) it was the original purpose of the study to examine handedness in twins, or (b) whether the study only reported data on handedness as a descriptive variable independent of the research question of the study. This analysis was run for the twins vs. singletons meta-analysis (meta-analysis set 1 ).

5. Sex ratio: As confirmed by a meta-analysis by Papadatou-Pastou et al. [4], males display higher rates of left-handedness than females. When numbers for males and females were reported, we investigated whether the male:female sex ratio had any moderating effect on ORs. This analysis was run for the twins vs. singletons meta-analysis (meta-analysis set 1 ). We did not perform analyses separately for males and females as data on handedness were rarely broken down by sex separately for twins and singletons.

6. Mean age of the participants: We investigated whether the mean age of the participants had any moderating effect on the ORs for atypical handedness between twins and singletons (meta-analysis set 1 ).

7. Type of singleton group: Since handedness is believed to be partially genetically determined, we investigated whether there was any moderating effect on the ORs for atypical handedness between twins and singletons (meta-analysis set 1 ) depending on (a) whether twins and singletons were genetically related (e.g., singletons were siblings of twins) or (b) not.

8. Handedness classification: We investigated whether the handedness classification had any moderating effect on the ORs for atypical handedness between twins and singletons (meta-analysis set 1 ). Here, we distinguished between the classification schemes of (a) "right vs. ambidextrous/mixed-handed vs. left" (R-A-L) and (b) "right vs. left" (R-L).

9. Method of handedness assessment: As it was shown that handedness assessment affects handedness outcomes [3], we investigated whether the assessment method had any moderating effect on the ORs for atypical handedness between twins and singletons (meta-analysis set 1 ). Those methods varied between (a) preference obtained from performance inventories in which the individuals' handedness was determined on the basis of more than one item and (b) self-reports/writing hand.

10. Method of determining zygosity: We investigated whether the method of determining zygosity had any moderating effect on the ORs in the MZ vs. DZ (meta-analysis set 2) and in the concordance 
Table 1 Results of meta-analysis set 1

\begin{tabular}{|c|c|c|c|}
\hline & Left-handedness & Mixed-handedness & Non-right-handedness \\
\hline \multirow[t]{4}{*}{ Studies (k) } & 19 & 5 & 20 \\
\hline & 13 included in [10] & 2 included in [10] & 13 included in [10] \\
\hline & 1 excluded from [10] & 3 new studies & 1 excluded from [10] \\
\hline & 5 new studies & & 6 new studies \\
\hline Individuals in total (n) & 189,422 & & \\
\hline Individuals per comparison ( $n$ ) & 188,922 & 39,123 & 189,274 \\
\hline Twins $(n)$ & 49,881 & 26,625 & 50,066 \\
\hline Singletons $(n)$ & 139,041 & 12,498 & 139,208 \\
\hline Prevalence in twins & $9.13 \%(n=4552)$ & $3.39 \%(n=903)$ & $11.11 \%(n=5564)$ \\
\hline Prevalence in singletons & $6.97 \%(n=9692)$ & $2.67 \%(n=334)$ & $7.23 \%(n=10,069)$ \\
\hline OR $[95 \% \mathrm{Cl}]$ & $1.40[1.26,1.57]$ & $1.08[0.52,2.27]$ & $1.36[1.22,1.52]$ \\
\hline z & $5.98^{* * *}$ & 0.21 & $5.65^{* * *}$ \\
\hline \multirow[t]{3}{*}{ Heterogeneity among studies } & $\mathrm{Q}(18)=45.42^{* * *}$ & $\mathrm{Q}(4)=10.39^{*}$ & $\mathrm{Q}(19)=37.94^{* *}$ \\
\hline & $1^{2}=60.39 \%$ & $I^{2}=72.68 \%$ & $I^{2}=61.06 \%$ \\
\hline & $\mathrm{Tau}^{2}=0.02$ & $\mathrm{Tau}^{2}=0.46$ & $\mathrm{Tau}^{2}=0.02$ \\
\hline
\end{tabular}

${ }^{* * *} p<0.001,{ }^{* *} p<0.01,{ }^{*} p<0.05$

analysis (meta-analysis set 3 ). In this context, we distinguished between (a) serological and genetic methods and (b) questionnaires and observational methods.

For most studies, not all the variables of interest were reported. Therefore, the number of studies included in each of the three sets of meta-analyses as well as in the moderator analyses varied. Hand skill was very rarely reported. In cases where hand skill and hand preference were reported [91], we opted to extract data for hand preference. When studies used handedness inventories containing several items but reported handedness prevalence for every item separately (e.g., Zheng et al. [35], we extracted data for writing hand, as this is the most commonly used measure for handedness [3].

Moderator analyses were conducted for the nonright-handedness and the left-handedness classification schemes. The mixed-handedness classification scheme included only $n=5$ and $n=10$ studies in meta-analysis set 1 and 2, respectively, therefore not allowing for this kind of analysis.

\section{Results}

Meta-analysis set 1: prevalence of atypical handedness in twins vs. singletons

The aim of the first set of meta-analyses was to reveal whether there was higher prevalence of atypical handedness (left-handedness, mixed-handedness, or non-righthandedness) in twins compared to singletons. Overall, 21 studies (13 included by Sicotte et al. [10], one excluded by Sicotte et al. [10], seven new studies) allowed for the calculation of ORs for twins vs. singletons, including $n=139,242$ singletons, and $n=50,180$ twin individuals, resulting in a total sample size of $n=189,422$ individuals.

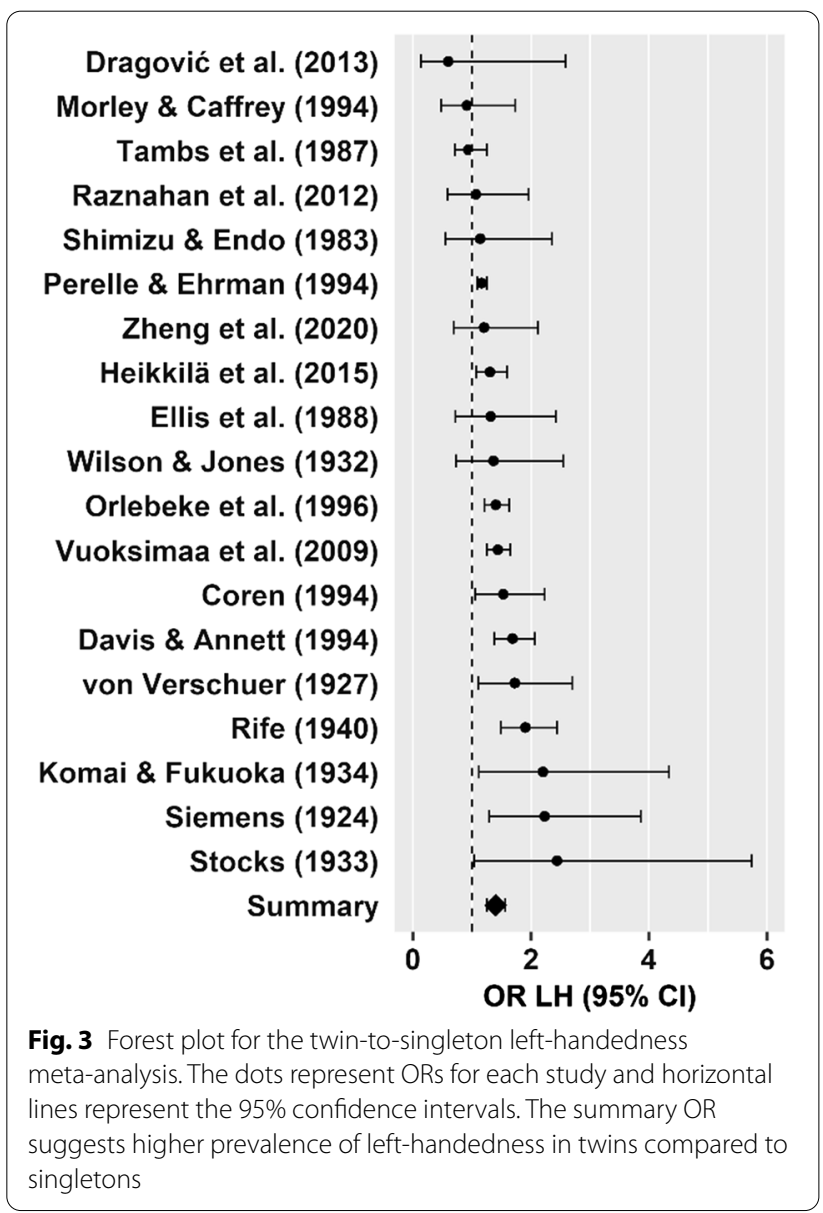


Left-handedness: The twin-to-singleton left-handedness OR provided evidence for a higher prevalence of left-handedness in twins (Table 1, Fig. 3) with moderate to high heterogeneity among the studies $(p<0.001)$. Neither Egger's regression test for funnel plot asymmetry $(z=0.11, p=0.909)$, visual inspection of the funnel plot (Fig. 4a), nor the trim and fill test (0 studies to impute, $\mathrm{SE}=2.67$ ) revealed evidence for small study bias.

Mixed-handedness: The twin-to-singleton OR did not suggest a difference in mixed-handedness prevalence between singletons and twins (Table 1). There was evidence for heterogeneity among the studies $(p<0.05)$. Neither Egger's regression test for funnel plot asymmetry $(z=0.90, p=0.369)$, visual inspection of the funnel plot (Fig. 4b), nor the trim and fill test (0 studies to impute, $\mathrm{SE}=1.43$ ) revealed evidence for small study bias.

Non-right-handedness: The twin-to-singleton OR suggested a higher prevalence of non-right-handedness in twins compared to singletons (Table 1, Fig. 5) with moderate to high heterogeneity among studies $(p<0.01)$. Neither Egger's regression test $(z=-0.04, p=0.967)$, nor visual inspection of the funnel plot (Fig. 4c) revealed evidence for small study bias. According to the trim and fill test, one study $(\mathrm{SE}=2.85)$ needs to be imputed to the right of the mean for the funnel plot to be symmetrical. The resulting adjusted OR was $1.37(95 \% \mathrm{CI}=[1.23$, $1.52], z=5.74, p<0.001)$.

Moderator analyses: Moderator analyses were conducted for both the non-right-handedness and the lefthandedness classification scheme, but only the findings of the non-right-handedness classification are reported, as this was the most inclusive. We report results for the left-handedness classification in case the results differed between classification systems. In each moderator analysis, we included all studies for which the potential moderator variable could be extracted (see Table 2).

Sicotte et al. (1999) meta-analysis: First, we were interested if twin-to-singleton ORs differed between studies included in the meta-analysis by Sicotte et al. [10] (13 studies), studies specifically excluded from the metaanalysis by Sicotte et al. [10] (one study, which was thus excluded from this analysis), and new studies (six studies). There was no evidence for a difference in twin-tosingleton ORs between studies included in Sicotte et al. [10] and new studies, $Q(1)=0.86, p=0.354$.

Publication year: There was no evidence for a moderating effect of publication year on twin-to-singleton ORs in the non-right-handedness classification, $Q(1)=3.52$,

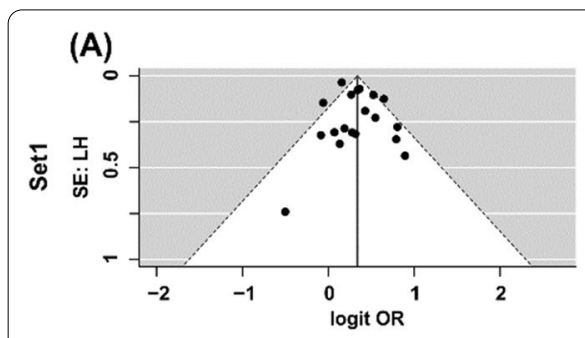

(D)

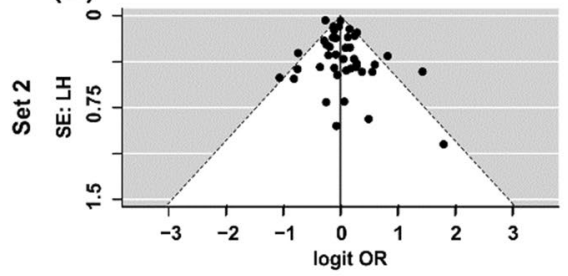

(G)

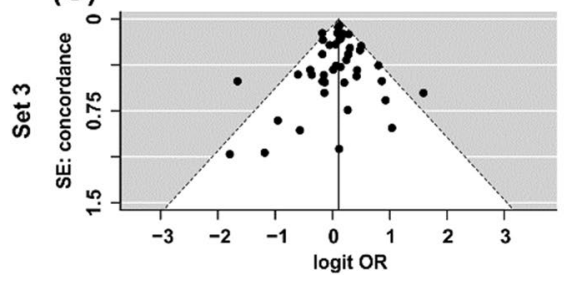

(B)

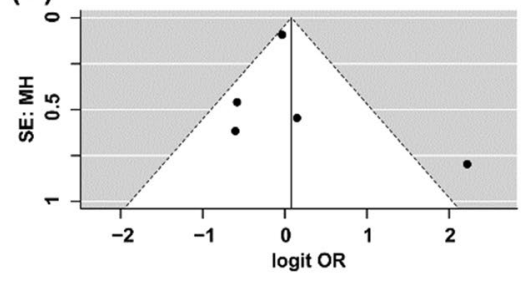

(E)

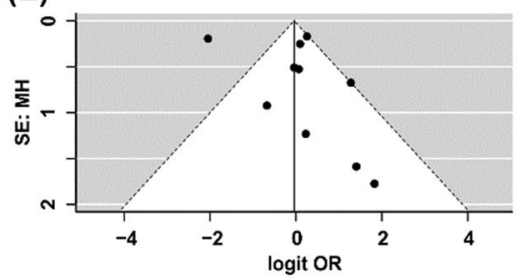

(C)

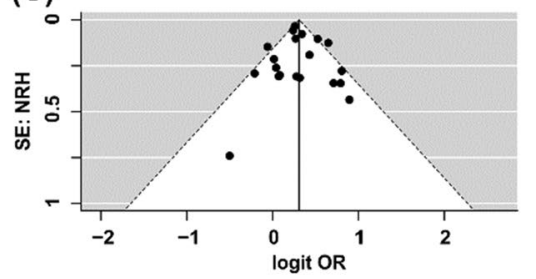

(F)

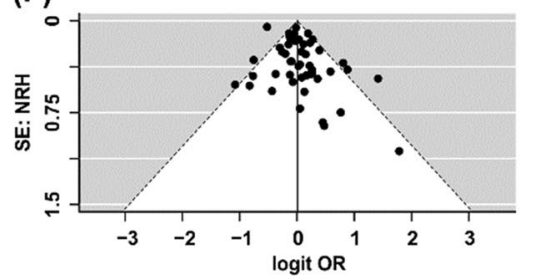

Fig. 4 Funnel plot of standard errors on logit prevalence. Funnel plots a "LH" (left-handedness), b "MH" (mixed-handedness), and c "NRH"(non-right-handedness) refer to meta-analysis set 1 (twins vs. singletons), and by means of a visual inspection no asymmetries could be identified. Funnel plots d "LH", e "MH", and f "NRH" refer to meta-analysis set 2 (DZ vs. MZ), and according to visual inspection we detected no asymmetries. Funnel plot $\mathbf{g}$ "concordance" refers to meta-analysis set 3 (concordance), and a visual inspection did not reveal any asymmetry 


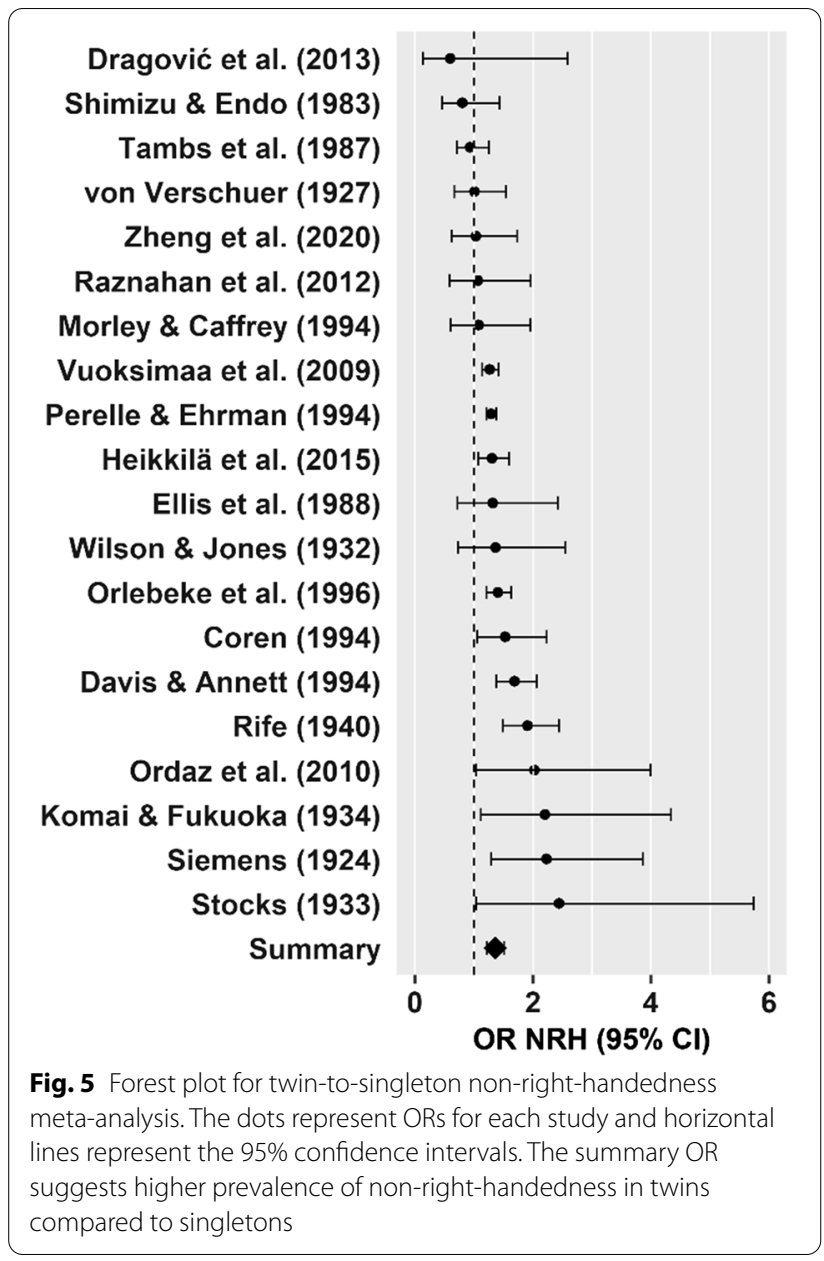

$p=0.061$. However, there was a significant effect of publication year on twin-to-singleton ORs in the lefthandedness classification, $Q(1)=7.23, \quad p<0.01$. The negative regression estimate $(-0.005, \mathrm{SE}=0.002,95 \%$ $\mathrm{CI}=-0.009,-0.001)$ suggests smaller ORs in more recent studies (Fig. 6a).

To test whether both older and more recent studies show a higher prevalence of atypical handedness in twins compared to singletons, we ran separate random effects meta-analyses on studies published before $1975(k=6$ studies including $n=21,372$ singletons and $n=2290$ twin individuals) and studies published after $1975(k=13$ studies including $n=117,669$ singletons and $n=47,591$ twin individuals). The twin-to-singleton left-handedness OR was estimated to be $1.90(95 \% \mathrm{CI}=[1.59,2.27]$, $z=6.98, p<0.001)$ in studies published before 1975 and $1.30(95 \% \mathrm{CI}=[1.17,1.45], z=4.75, p<0.001)$ in studies published after 1975.

Next, we were interested whether the decrease in ORs with publication year can be explained by an increase in left-handedness prevalence in singletons or a decrease of left-handedness prevalence in twins, or both. We ran random effects meta-analyses on the prevalence of left-handedness in twins and singletons separately and included publication year as a moderating variable. There was no evidence for a moderating effect of publication year on left-handedness prevalence in twins $(Q(1)=0.002$, $p=0.968$, Fig. 6b). There was, however, a trend towards higher left-handedness prevalence in more recent studies in singletons $(Q(1)=3.80, p=0.051$, Fig. 6c).

Ancestry: Next, we aimed to test for a moderating effect of ancestry. Ancestry was extracted from 19 studies

Table 2 Twin-to-singleton ORs in the different levels of the categorial moderator variables within the non-right-handedness (NRH) comparison. Overall, 20 studies were included in the NRH comparison (see main text).

\begin{tabular}{|c|c|c|c|c|c|c|}
\hline Variable & Levels & Studies $(k)$ & Participants (n) & Twins & Singletons & $\begin{array}{l}\text { twin-to-singleton } \\
\text { NRH OR }[95 \% \mathrm{Cl}]\end{array}$ \\
\hline \multirow[t]{2}{*}{ Sicotte et al. [10] meta-analysis } & Yes (included in Sicotte et al. [10]) & 13 & 85,371 & 8281 & 77,090 & $1.43[1.23,1.66]$ \\
\hline & No (new study) & 6 & 38,394 & 30,773 & 7621 & $1.26[1.01,1.57]$ \\
\hline \multirow[t]{2}{*}{ Ancestry } & Europe/USA/Australia & 16 & 101,828 & 38,090 & 63,738 & $1.40[1.23,1.59]$ \\
\hline & East Asia & 3 & 21,937 & 964 & 20,973 & $1.16[0.79,1.72]$ \\
\hline \multirow[t]{2}{*}{ Study purpose } & Handedness in twins & 17 & 187,645 & 49,375 & 138,270 & $1.38[1.23,1.54]$ \\
\hline & Other purpose & 3 & 1629 & 691 & 938 & $1.21[0.85,1.74]$ \\
\hline \multirow[t]{2}{*}{ Type of singleton group } & Genetically related to the twins & 4 & 77,763 & 15,614 & 62,149 & $1.31[1.07,1.60]$ \\
\hline & Genetically unrelated to the twins & 12 & 103,122 & 33,799 & 69,323 & $1.41[1.22,1.63]$ \\
\hline \multirow[t]{2}{*}{ Handedness classification } & $R-A-L$ & 4 & 38,975 & 26,511 & 12,464 & $1.12[0.87,1.45]$ \\
\hline & $R-L$ & 12 & 83,177 & 11,852 & 71,325 & $1.45[1.26,1.68]$ \\
\hline \multirow[t]{2}{*}{ Method of handedness assessment } & $\begin{array}{l}\text { Preference obtained from invento- } \\
\text { ries containing more than one item }\end{array}$ & 5 & 16,721 & 1560 & 15,161 & $1.57[1.26,1.95]$ \\
\hline & Self-reports/writing hand & 12 & 170,689 & 47,700 & 122,989 & $1.32[1.19,1.47]$ \\
\hline
\end{tabular}



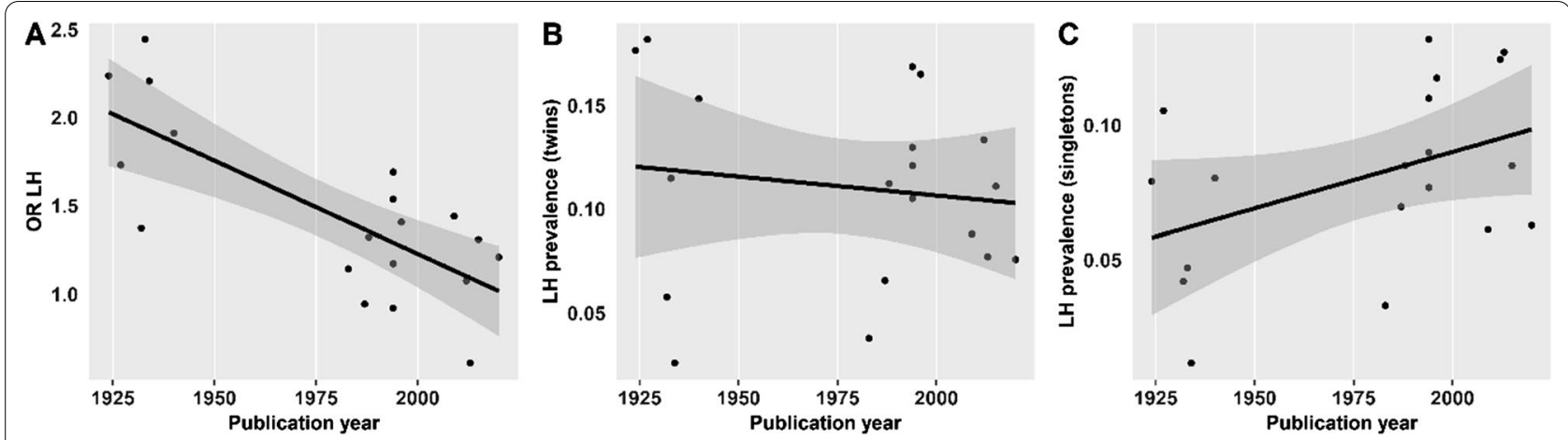

Fig. 6 a Moderating effect of publication year on twin-to-singleton ORs for left-handedness. The twin-to-singleton OR for left-handedness decreases as the publication year of the individual study increases. This effect could be due to a decrease in left-handedness prevalence in twins, an increase in left-handedness prevalence in singletons, or both. $\mathbf{b}$ Association between publication year and left-handedness prevalence in twins. $\mathbf{c}$ Association between publication year and left-handedness prevalence in singletons

reporting data on non-right-handedness and resulted in 16 studies of European/US American/Australian origin and three studies of East Asian origin. There was no evidence for a moderating effect of ancestry on twin-to-singleton ORs, $Q(1)=0.76, p=0.383$.

Study purpose: Next, we tested whether there was evidence for a moderating effect of whether the purpose of the original study was to examine the handedness in twins (17 studies) or not (three studies). There was no evidence for a moderating effect of purpose on twin-tosingleton ORs, $Q(1)=0.43, p=0.510$.

Sex: We tested whether sex ratio (extracted from nine studies) had any moderating effect. There was no evidence for a moderating effect of sex ratio on twin-to-singleton ORs, $Q(1)=0.20, p=0.653$.

Mean age: Likewise, there was no evidence for a moderating effect of mean age (extracted from seven studies) on twin-to-singleton ORs, $Q(1)=2.07, p=0.151$.

Type of singleton group: Furthermore, we investigated any potential effect of the type of singleton group on twin-to-singleton ORs. We distinguished between studies including singleton samples which were genetically related with the twin sample (four studies) and studies including singleton samples which were not genetically related with the twins (twelve studies). There was no evidence for a moderating effect of singleton group type on twin-to-singleton ORs, $Q(1)=0.37, p=0.541$.

Handedness classification: Next, we investigated a potential moderating effect of handedness classification, divided into "R-A-L" (four studies) and "R-L" (twelve studies). There was no evidence for a moderating effect of classification on twin-to-singleton ORs, $Q(1)=3.03$, $p=0.082$.

Method of handedness assessment: Last, we aimed to reveal potential moderating effects of the method of handedness assessment. To this end, we compared preference obtained from performance inventories in which the individuals' handedness was determined on the basis of more than one item (five studies) and selfreports/writing hand (twelve studies). There was no evidence for a moderating effect of handedness assessment on twin-to-singleton ORs, $Q(1)=1.87, p=0.171$.

\section{Meta-analysis set 2: prevalence of atypical handedness in $\mathrm{MZ}$ vs. $\mathrm{DZ}$}

In our second set of meta-analyses, we aimed to investigate whether there was a difference in the prevalence of atypical handedness between $\mathrm{DZ}$ and $\mathrm{MZ}$ twins. Overall, 48 studies allowed for the calculation of MZ-to-DZ ORs, including $n=36,043 \mathrm{DZ}$ individuals and $n=27,252 \mathrm{MZ}$ individuals, resulting in a total sample size of $n=63,295$ individuals.

Left-handedness: The MZ-to-DZ OR revealed no evidence for a difference in left-handedness prevalence between MZ and DZ twins (Table 3). Heterogeneity among the studies was moderate $(p=0.002)$. Neither Egger's regression test for funnel plot asymmetry $(z=1.34, p=0.182)$, nor visual inspection of the funnel plot (Fig. 4d) revealed evidence for small study bias. However, according to the trim and fill test, six studies $(\mathrm{SE}=4.32)$ would need to be imputed to the left of the mean in order for the funnel plot to be symmetrical. The resulting adjusted OR was $0.94(95 \% \mathrm{CI}=[0.85,1.03]$, $z=-1.35, p=0.178$ ).

Mixed-handedness: The MZ-to-DZ mixed-handedness OR did not provide evidence for a difference in mixedhandedness prevalence between MZ and DZ twins (Table 3). Heterogeneity among the studies was high $(p<0.001)$. Neither Egger's regression test for funnel plot asymmetry $(z=1.49, p=0.137)$, nor visual inspection of the funnel plot (Fig. 4e) revealed evidence for small 
Table 3 Results of meta-analysis set 2

\begin{tabular}{|c|c|c|c|}
\hline & Left-handedness & Mixed-handedness & Non-right-handedness \\
\hline \multirow[t]{4}{*}{ Studies $(k)$} & 43 & 10 & 47 \\
\hline & 27 included in [10] & 5 included in [10] & 28 included in [10] \\
\hline & 3 excluded from [10] & 5 new studies & 3 excluded from [10] \\
\hline & 13 new studies & & 16 new studies \\
\hline Individuals in total (n) & 63,295 & & \\
\hline Individuals per comparison ( $n$ ) & 59,973 & 28,511 & 63,181 \\
\hline MZ twins $(n)$ & 25,957 & 10,164 & 27,203 \\
\hline DZ twins $(n)$ & 34,016 & 18,347 & 35,978 \\
\hline Prevalence in $\mathrm{MZ}$ twins & $11.45 \%(n=2971)$ & $1.83 \%(n=186)$ & $12.08 \%(n=3286)$ \\
\hline Prevalence in DZ twins & $11.82 \%(n=4019)$ & $3.26 \%(n=599)$ & $13.29 \%(n=4780)$ \\
\hline OR $[95 \% \mathrm{Cl}]$ & $0.98[0.89,1.07]$ & $0.96[0.46,1.99]$ & $1.01[0.91,1.12]$ \\
\hline$z$ & -0.51 & -0.11 & 0.13 \\
\hline \multirow[t]{3}{*}{ Heterogeneity among studies } & $\mathrm{Q}(42)=74.08^{* *}$ & $\mathrm{Q}(9)=100.52^{* * *}$ & $Q(46)=149.78^{* * *}$ \\
\hline & $1^{2}=36.00 \%$ & $I^{2}=86.33 \%$ & $I^{2}=57.63 \%$ \\
\hline & $\mathrm{Tau}^{2}=0.02$ & $\operatorname{Tau}^{2}=0.88$ & $\mathrm{Tau}^{2}=0.05$ \\
\hline
\end{tabular}

${ }^{* * *} p<0.001, * * p<0.01$

study bias. According to the trim and fill test, four studies $(S E=2.02)$ would need to be imputed to the left of the mean in order for the funnel plot to be symmetrical. The resulting adjusted OR was $0.61(95 \% \mathrm{CI}=[0.31,1.20]$, $z=-1.43, p=0.152$ ).

Non-right-handedness: The MZ-to-DZ non-righthandedness OR did not provide evidence for a difference in non-right-handedness prevalence between MZ and DZ twins (Table 3). Heterogeneity among the studies was moderate $(p<0.001)$. Neither Egger's regression test for funnel plot asymmetry $(z=1.73, p=0.083)$, nor visual inspection of the funnel plot (Fig. 4f) revealed evidence for small study bias. However, according to the trim and fill test, eight studies $(\mathrm{SE}=4.54)$ would need to be imputed to the left of the mean in order for the funnel plot to be symmetrical. The resulting adjusted OR was $0.94(95 \% \mathrm{CI}=[0.84,1.06], z=-1.00, p=0.320)$.

Moderator analysis: There was no evidence for a difference in MZ-to-DZ non-right-handedness ORs between studies included in Sicotte et al. [10] (28 studies), studies excluded by Sicotte et al. [10] (three studies) and new studies (16 studies), $Q(2)=0.75, p=0.687$.

We then investigated a potential moderating effect of the method used to determine zygosity on MZ-to-DZ ORs. Studies were divided into "serological and genetic analyses" (eleven studies) and "questionnaire" (25 studies). There was no evidence for a moderating effect of the method used to determine zygosity on MZ-to-DZ nonright-handedness ORs, $Q(1)=0.06, p=0.809$.

\section{Meta-analysis set 3: concordance of handedness in MZ vs. DZ}

The aim of our third set of meta-analyses was to test whether DZ and MZ twin pairs differed in pairwise handedness concordance. Overall, 44 studies (27 included by Sicotte et al. [10], one study excluded by Sicotte et al. [10], 16 new studies) allowed for the calculation of ORs for pairwise concordance in $\mathrm{MZ}$ vs. DZ twins, including $n=20,711 \mathrm{DZ}$ twin pairs and $n=15,506 \mathrm{MZ}$ twin pairs, resulting in a total sample size of $n=36,217$ twin pairs. Across all studies, the concordance rate was $80.49 \%$ in MZ twin pairs ( $n=12,481$ concordant twin pairs) and $79.27 \%$ in DZ twin pairs $(n=16,417$ concordant twin pairs).

The concordance OR was estimated to be 1.11 (95\% $\mathrm{CI}=[1.06,1.18], z=3.91, p<0.001$, Fig. 7). Heterogeneity among the studies was low, $Q(43)=60.01, p<0.05$, $I^{2}=0.02 \%$, Tau ${ }^{2}=0.00$. Neither Egger's regression test for funnel plot asymmetry $(z=-0.54, p=0.590)$, nor visual inspection of the funnel plot (Fig. $4 \mathrm{~g}$ ) revealed evidence for small study bias. According to the trim and fill test, one study $(\mathrm{SE}=4.10)$ would need to be imputed to the right of the mean in order for the funnel plot to be symmetrical. The resulting adjusted OR was $1.12(95 \%$ $\mathrm{CI}=[1.06,1.18], z=3.96, p<0.001)$.

There was no evidence for a difference in MZ-to-DZ concordance ORs between studies included by Sicotte et al. [10] (27 studies), excluded by Sicotte et al. [10] (one study, which was thus excluded from this analysis), and new studies (16 studies), $Q(1)=0.88, p=0.349$.

Likewise, there was no evidence for a moderating effect of the method used to determine zygosity on 


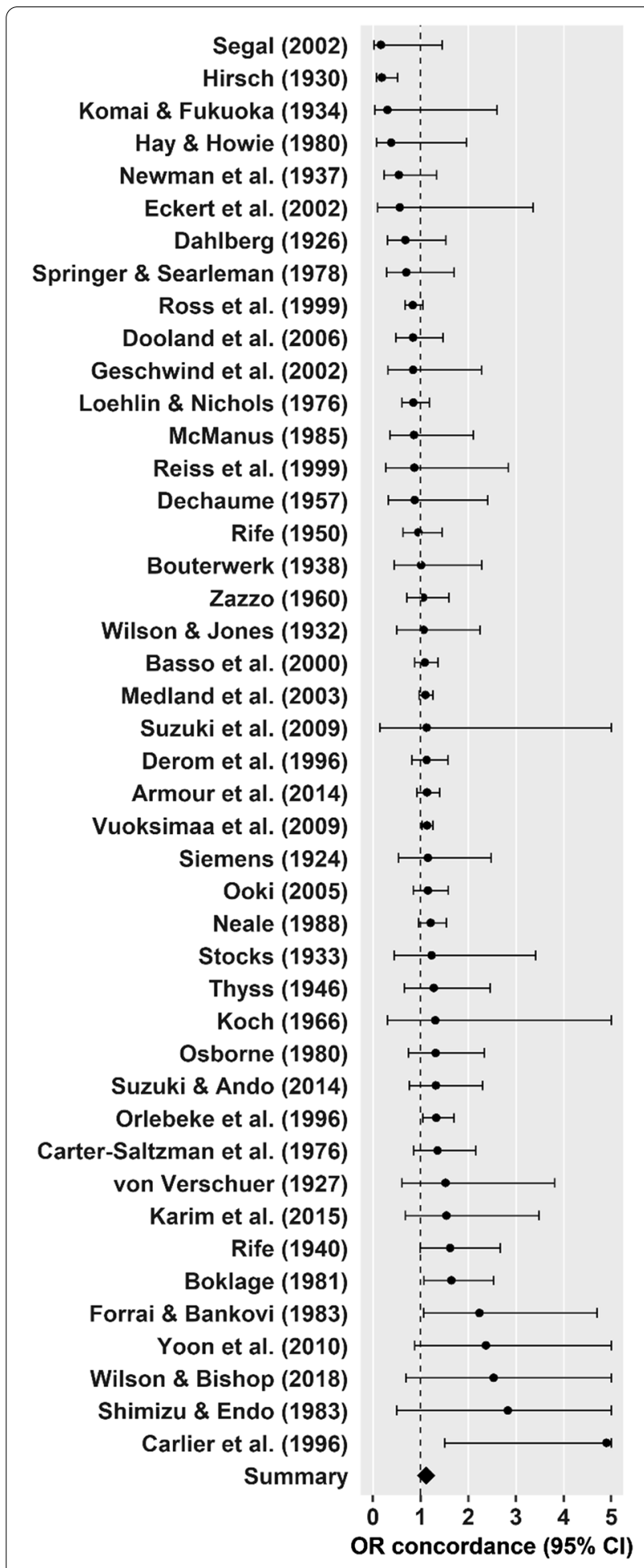

Fig. 7 Forest plot for MZ-to-DZ concordance meta-analysis. The dots represent ORs for each study and horizontal lines represent the 95\% confidence intervals. The summary OR suggests a slightly higher handedness concordance in MZ twins compared to DZ twins concordance ORs, $Q(1)=0.04, p=0.834$, suggesting that there was no difference between studies using genetic and/or serological analyses (twelve studies) and studies using questionnaire methods (22 studies) to determine zygosity.

\section{Discussion}

In three sets of meta-analyses, we examined the influence of twin status and twin zygosity on handedness prevalence and handedness concordance. Our first set of meta-analyses confirmed that in line with Sicotte et al. [10], left-handedness ( $\mathrm{OR}=1.40$, Fig. 3) and nonright-handedness ( $\mathrm{OR}=1.36$, Fig. 5) occur more often among twins than among singletons. Moderator analyses found elevated levels of non-right-handedness among twins to be independent of all variables tested with respect to a potential moderating effect. However, we found that more recent studies reported smaller differences in prevalence of left-handedness between twins and singletons (Fig. 6). To test whether there is a higher left-handedness prevalence in twins compared to singletons in more recent studies at all, we estimated twin-tosingleton ORs for left-handedness for studies published pre and post 1975 separately. With a pre-1975 OR of $1.90(95 \% \mathrm{CI}=[1.59,2.27])$ and a post-1975 OR of 1.30 $(95 \% \mathrm{CI}=[1.17,1.45])$, ORs for more recent studies were smaller, but still indicated a significant twin effect on left-handedness.

Overall, the decrease in twin-to-singleton ORs might either be explained by a decrease in left-handedness in twins or an increase of left-handedness in singletons, or both. As already mentioned, complications occur more often in the course of multiple births [11-13], which might contribute to the development of atypical handedness [10]. However, most individual studies included in our meta-analysis did not provide information on pre- or perinatal conditions, so we could not test for a moderating effect of these conditions on the twin-to-singleton OR. Along these lines, future research might have a closer look on the relation between birth complications and handedness.

Assuming that higher proportions of left-handedness among twins might be the by-product of birth complications, a decrease in atypical handedness in twins must be assigned to a decrease in the occurrence of these complications. In fact, it is well conceivable that medical progress over the last decades, that is clearly detectable, e.g. in the United States [92, 93], may have helped to equalize the risks associated with multiple and single births. Such assumptions are supported by a study by Heikkilä et al. [77] who showed differences in left-handedness in twins and singletons to disappear when controlling for birth weight, Apgar score, and gestational age. We therefore 
tested whether there is evidence for a decrease in lefthandedness prevalence in twins (Fig. 6b) by running meta-analyses on left-handedness prevalence in twins and singletons separately while including publication year as a moderator variable. However, while there was no evidence for an effect of publication year on left-handedness prevalence in twins, there seemed to be a trend towards an increase of left-handedness prevalence in singletons (Fig. 6c).

The overall prevalence of atypical handedness in our study was lower than expected. We found $9.13 \%$ of twins and $6.97 \%$ of singletons to be left-handed (Table 1), while Papadatou-Pastou et al. [3] reported a figure of $10.6 \%$ (95\% CI $9.71 \%, 11.50 \%)$ for the general population. The low values in our study might be the result of a general effect of publication year in singletons, given that the prevalence of left-handedness has been shown to be higher in younger than in older cohorts $[25,94,95]$. The social stigma associated with left-handedness in the last century [96] may have driven left-handers to conceal their preference in self-reports [97] and to retrain to use their right hand [25, 98]. Most of the studies included in our meta-analysis were published in the previous century and their participants could have been subjected to environmental pressures against left-handedness, leading to underestimation of the true population prevalence of left-handedness. Similarly, we found low overall prevalence of mixed-handedness $(3.39 \%$ in twins and $2.67 \%$ in singletons, Table 1), whereas Papadatou-Pastou et al. [3] gave a point estimate of $9.3 \%$ for the general population. This might also be due to an effect of publication year. Moreover, three of five studies that provided data for mixed-handedness classified handedness as writing hand so that data extracted from these studies most likely reflect not mixed-handedness, but ambidexterity, which is much rarer [99].

Our second set of meta-analyses found no difference in the prevalence of atypical handedness between $\mathrm{MZ}$ and DZ twins (left-handedness OR $=0.98$, mixed-handedness $\mathrm{OR}=0.96$, non-right-handedness $\mathrm{OR}=1.01$, Table 3). This result is consistent with the meta-analysis by Sicotte et al. [10] who interpreted this null-effect as indication against mirror imaging theories designed to explain heightened frequencies of left-handers and frequent handedness discordance among MZ twins [100-102]. Indeed, it weakens the hypothesis suggesting that the monozygotic twinning process is responsible for atypical handedness [10]. Moreover, it indicates that the overall heightened frequencies of left- and nonright-handers among twins are independent of the twins' zygosity. A moderator analysis showed that this effect was not influenced by the method used to determine the twins' zygosity, thus refuting the idea that the result was affected by the accuracy with which twins were classified as monozygotic or dizygotic. All in all, revealing comparable prevalence of atypical handedness for $\mathrm{MZ}$ and $\mathrm{DZ}$ twins cannot enrichen knowledge about genetic contribution to handedness per se. As already recognized by Sicotte et al. [10], to do so, it is crucial to look at pairwise handedness concordance or discordance of MZ and DZ twin pairs.

Our third set of meta-analyses found a small yet significant effect ( $O R=1.11$, Fig. 7) for higher handedness concordance among MZ (80.49\%) as compared to DZ $(79.27 \%)$ twins, consistent with the meta-analysis by Sicotte et al. [10]. Even though other publications have demonstrated the occurrence of handedness discordance among MZ twin pairs [100, 101, 103, 104], it was estimated to concern a minority of $20-25 \%$ of cases [2]. Stronger phenotypic variation among DZ compared to $M Z$ pairs indicates a certain genetic foundation of that phenotype $[2,26]$. Therefore, our results confirm handedness to rely on genetic factors to some extent [10] and are consistent with heritability estimates of $0.24-0.26$ [31-33]. A moderator analysis suggested that the frequencies of handedness concordance did not differ between studies included in the meta-analysis by Sicotte et al. [10], studies explicitly excluded from Sicotte et al. [10], and more recent studies.

To allow future meta-analyses to perform comparisons on handedness prevalence in twins more specifically (e.g., handedness in male vs. female twins, or handedness in same sex pairs vs. opposite sex pairs), it is desirable that researchers report results broken down for parameters like zygosity, sex, and consider data on birth complications. As this might be beyond the scope of individual papers, we encourage authors to provide open raw data in publicly accessible repositories such as the osf.io.

The present study is not without limitations. We did not investigate relative hand skill but were restricted to hand preference. Measuring hand preference is far more established as compared to assessing relative hand skill, as it is easier and more convenient [105]. Most of the studies included in our meta-analysis only provided information on hand preference, not allowing for an additional analysis for hand skill. Moreover, hand preference and hand skill correlate to some extent [106-108], and the distribution of handedness categories overlaps for preference- and skill-related criterions in $90 \%$ of the cases [109].

Similarly, our study only dealt with handedness direction in terms of categorial handedness classification which does not take into account the fact that individual handedness can further be defined regarding its strength or its degree. Along these lines, other approaches consider handedness as a continuum, 
extending the question to how strong or how consistently one hand is preferred, used, or skilled over the other. Indeed, several findings obtained within laterality research on associations between handedness and structural brain lateralization [110] or cognitive performance $[111,112]$ as well as concerning the genetic foundation of handedness $[113,114]$ are linked to strength but not direction of handedness. However, since most studies included in the present meta-analyses did not assess handedness in a continuous manner, we were unable to account for handedness strength. Therefore, it falls to future studies to extend their assessment repertoire by measures of handedness strength.

From a methodological point of view, it is further crucial to mention that overall, our moderator analyses are low in power due to the investigated study sample sizes. Of note, in some cases, moderator levels included only three data points calling for an interpretation of these findings with caution.

\section{Conclusion}

To summarize, our analyses provide evidence for increased frequencies of left- and non-right-handedness among twins compared to singletons but do not support the notion of elevated prevalence of atypical handedness among MZ compared to DZ twins. Therefore, our findings are in line with the interpretation that twin or multiple births may be accompanied by certain environmental conditions that disturb the establishment of righthandedness. Moreover, our analysis showed that the prevalence of atypical handedness seems to be steadily equalizing for twins and singletons over time. Indeed, the last decades may have advanced medical progress so that the occurrence of risks associated twin births that mediate the shift towards non-right-handedness is aligned with the occurrence of these risks within single births. However, separate analysis in twins and singletons suggests that this effect is rather the product of an increase of left-handedness prevalence in singletons rather than a decrease of left-handedness prevalence in twins. As we further showed MZ twins to be more frequently handedness concordant than DZ twins, we can confirm a partially genetic foundation of phenotypic handedness which, however, does not seem to account for the vast majority of this trait. We generally acknowledge phenotypic handedness to arise from a complex interaction of genetic and environmental influences that can only be understood by means of multi-level approaches. Specifying how handedness evolves should finally serve to comprehend the population level predominance of right-handedness as well as the overrepresentation of atypical handedness in samples like twins.

\section{Abbreviations}

DZ: Dizygotic; EHI: Edinburgh handedness inventory; MZ: Monozygotic; OR: Odds ratio; LH: Left-handedness; $\mathrm{MH}$ : Mixed-handedness; $\mathrm{NRH}$ :

Non-right-handedness.

\section{Supplementary Information}

The online version contains supplementary material available at https://doi. org/10.1186/s40359-021-00695-3.

Additional file 1. Supplementary table 1.

Additional file 1. PRISMA guidelines.

\section{Acknowledgements}

The authors want to express their gratitude to Dorothy V. M. Bishop for her positive responses to data requests. We further thank our reviewers for their positive and constructive feedback on our manuscript. We acknowledge support by the Open Access Publication Funds of the Ruhr-Universität Bochum [115-145].

\section{Authors' contributions}

LSP collected and extracted the data and wrote the manuscript. JS analysed the data and wrote the manuscript. MPP, JP, SP, and SO conceived the study and consulted on data analysis. All authors read and approved the final manuscript.

\section{Funding}

Open Access funding enabled and organized by Projekt DEAL. JS is funded by the Deutsche Forschungsgemeinschaft (DFG, German Research Foundation, 418445085). SP is funded by the Royal Society (UF150663).

\section{Availability of data and materials}

All data and analysis codes are available in the OSF project "Handedness in Twins: Meta-Analyses" under the link: https://osf.io/w7jem/ (the project was preregistered under the link: https://osf.io/ywhsj). Analyses were conducted as planed in the preregistration and there were no deviations from the preregistered research protocol.

\section{Declarations}

Ethics approval and consent to participate

Not applicable.

\section{Consent for publication}

Not applicable.

\section{Competing interests}

The authors declare that they have no competing interests.

\section{Author details \\ ${ }^{1}$ Cognitive Psychology, Institute of Cognitive Neuroscience, Faculty of Psy- chology, Ruhr University Bochum, Universitätsstraße 150, 44780 Bochum, Germany. ${ }^{2}$ School of Medicine, University of St Andrews, St Andrews, Scotland. ${ }^{3}$ School of Education, Department of Primary Education, National and Kapo- distrian University of Athens, Athens, Greece. ${ }^{4}$ Biomedical Research Founda- tion of the Academy of Athens, Athens, Greece. ${ }^{5}$ Institute of Systems Medicine and Department of Human Medicine, MSH Medical School Hamburg, Hamburg, Germany. ${ }^{6}$ Department of Psychology, Medical School Hamburg, Hamburg, Germany.}

Received: 17 March 2021 Accepted: 24 November 2021

Published online: 15 January 2022 


\section{References}

1. Güntürkün O, Ströckens F, Ocklenburg S. Brain lateralization: a comparative perspective. Physiol Rev. 2020;100:1019-63. https://doi.org/10. 1152/physrev.00006.2019.

2. Ooki S. An overview of human handedness in twins. Front Psychol. 2014;5:10. https://doi.org/10.3389/fpsyg.2014.00010.

3. Papadatou-Pastou M, Ntolka E, Schmitz J, Martin M, Munafò MR, Ocklenburg S, Paracchini S. Human handedness: a meta-analysis. Psychol Bull. 2020;146:481-524. https://doi.org/10.1037/bul0000229.

4. Papadatou-Pastou M, Martin M, Munafò MR, Jones GV. Sex differences in left-handedness: a meta-analysis of 144 studies. Psychol Bull. 2008;134:677-99. https://doi.org/10.1037/a0012814.

5. *Davis A, Annett M. Handedness as a function of twinning. Age and Sex Cortex. 1994;30:105-11. https://doi.org/10.1016/s0010-9452(13) 80326-7.

6. *Rife DC. Handedness, with special reference to twins. Genetics. 1940;25:178-86

7. Williams CS, Buss KA, Eskenazi B. Infant resuscitation is associated with an increased risk of left-handedness. Am J Epidemiol. 1992;136:277-86.

8. *Tambs K, Magnus P, Berg K. Left-handedness in twin families: support of an environmental hypothesis. Percept Mot Skills. 1987;64:155-70. https://doi.org/10.2466/pms.1987.64.1.155.

9. *Ellis SJ, Ellis PJ, Marshall E. Hand preference in a normal population. Cortex. 1988;24:157-63. https://doi.org/10.1016/s0010-9452(88) 80025-x.

10. Sicotte NL, Woods RP, Mazziotta JC. Handedness in twins: a meta-analysis. Laterality. 1999:4:265-86. https://doi.org/10.1080/713754339.

11. Baldwin VJ. Pathology of multiple pregnancy. New York: Springer Science \& Business Media; 1994.

12. Elster N. Less is more: the risks of multiple births. Fertil Steril. 2000;74:617-23.

13. Jones HW. Twins or more. Fertil Steril. 1995;63:701-2.

14. Bakan P, Dibb G, Reed P. Handedness and birth stress. Neuropsychologia. 1973;11:363-6. https://doi.org/10.1016/0028-3932(73)90050-X.

15. Hicks RA, Dusek C, Larsen F, Williams S, Pellegrini RJ. Birth complications and the distribution of handedness. Cortex. 1980;16:483-6.

16. Leiber $\mathrm{L}$, Axelrod $\mathrm{S}$. Not all sinistrality is pathological. Cortex 1981;17:259-71.

17. Ross G, Lipper EG, Auld PA. Hand preference of four-year-old children: its relationship to premature birth and neurodevelopmental outcome. Dev Med Child Neurol. 1987;29:615-22.

18. Coren S. Family patterns in handedness: evidence for indirect inheritance mediated by birth stress. Behav Genet. 1995;25:517-24. https:// doi.org/10.1007/BF02327575.

19. McManus IC. Handedness and birth stress. Psychol Med. 1981;11:485-96.

20. Barnes F. Temperament, adaptability, and left-handers. New Scientist. 1975;67:202-3.

21. O'Callaghan MJ, Tudehope DI, Dugdale AE, Mohay H, Burns Y, Cook F. Handedness in children with birthweights below $1000 \mathrm{~g}$. The Lancet. 1987:329:1155.

22. van Strien JW, Bouma A, Bakker DJ. Birth stress, autoimmune diseases, and handedness. J Clin Exp Neuropsychol. 1987;9:775-80. https://doi. org/10.1080/01688638708405216.

23. Saigal S, Rosenbaum P, Szatmari P, Hoult L. Non-right handedness among ELBW and term children at eight years in relation to cognitive function and school performance. Dev Med Child Neurol. 1992;34:425-33.

24. Heikkilä K, van Beijsterveldt CEM, Haukka J, livanainen M, Saari-Kemppainen A, Silventoinen K, et al. Triplets, birthweight, and handedness. Proc Natl Acad Sci U S A. 2018;115:6076-81. https://doi.org/10.1073/ pnas.1719567115

25. de Kovel CG, Carrión-Castillo A, Francks C. A large-scale population study of early life factors influencing left-handedness. Sci Rep. 2019;9:584. https://doi.org/10.1038/s41598-018-37423-8.

26. Neale MC, Cardon LR. Methodology for genetic studies of twins and families (Vol. 67): Springer Science \& Business Media; 2013.

27. Galton F. The history of twins, as a criterion of the relative powers of nature and nurture. Fraser's Magazine. 1875;12:566-76.

28. *Zazzo R. Les jumeaux: Le couple et la personne. Paris: Presses Universitaires de France; 1960
29. McManus IC. Handedness in twins: a critical review. Neuropsychologia. 1980;18:347-55.

30. McManus IC, Bryden MP. The genetics of handedness, cerebral dominance and lateralization. In: Rapin I, Segalowitz SJ, editors. Handbook of neuropsychology. Amsterdam; 1992.

31. Medland SE, Duffy DL, Wright MJ, Geffen GM, Martin NG. Handedness in twins: joint analysis of data from 35 samples. Twin Res Hum Genet. 2006;9:46-53. https://doi.org/10.1375/twin.9.1.46.

32. Medland SE, Duffy DL, Wright MJ, Geffen GM, Hay DA, Levy F, et al. Genetic influences on handedness: data from 25,732 Australian and Dutch twin families. Neuropsychologia. 2009;47:330-7. https://doi.org/ 10.1016/j.neuropsychologia.2008.09.005.

33. Somers M, Ophoff RA, Aukes MF, Cantor RM, Boks MP, Dauwan M, et al. Linkage analysis in a Dutch population isolate shows no major gene for left-handedness or atypical language lateralization. J Neurosci. 2015;35:8730-6. https://doi.org/10.1523/JNEUROSCI.3287-14.2015.

34. Cuellar-Partida G, Tung JY, Eriksson N, Albrecht E, Aliev F, Andreassen OA, et al. Genome-wide association study identifies 48 common genetic variants associated with handedness. Nat Hum Behav. 2020. https://doi.org/10.1038/s41562-020-00956-y.

35. *Zheng M, McBride C, Ho CS-H, Chan JK-C, Choy KW, Paracchini S. Prevalence and heritability of handedness in a Hong Kong Chinese twin and singleton sample. BMC Psychol. 2020;8:37. doi:https://doi.org/ 10.1186/s40359-020-00401-9.

36. *Medland SE, Wright MJ, Geffen GM, Hay DA, Levy F, Martin NG, Duffy DL. Special twin environments, genetic influences and their effects on the handedness of twins and their siblings. Twin Res Hum Genet. 2003;6:119-30.

37. Maxwell SE, Lau MY, Howard GS. Is psychology suffering from a replication crisis? What does "failure to replicate" really mean? Am Psychol. 2015:70:487-98. https://doi.org/10.1037/a0039400.

38. Markou P, Ahtam B, Papadatou-Pastou M. Elevated levels of atypical handedness in autism: meta-analyses. Neuropsychol Rev. 2017;27:25883. https://doi.org/10.1007/s11065-017-9354-4.

39. Papadatou-Pastou M, Sáfár A. Handedness prevalence in the deaf: meta-analyses. Neurosci Biobehav Rev. 2016;60:98-114. https://doi.org/ 10.1016/j.neubiorev.2015.11.013.

40. Papadatou-Pastou M, Tomprou D-M. Intelligence and handedness: meta-analyses of studies on intellectually disabled, typically developing, and gifted individuals. Neurosci Biobehav Rev. 2015;56:151-65. https://doi.org/10.1016/j.neubiorev.2015.06.017.

41. Nastou E, Ocklenburg S, Papadatou-Pastou M. Handedness in ADHD: Meta-Analyses; 2020.

42. Beukelaar LJ, Kroonenberg PM. Changes over time in the relationship between hand preference and writing hand among left-handers. Neuropsychologia. 1986;24:301-3.

43. Brackenridge CJ. Secular variation in handedness over ninety years. Neuropsychologia. 1981;19:459-62. https://doi.org/10.1016/00283932(81)90076-2.

44. Levy J. Psychobiological implications of bilateral asymmetry. In: Dimond S, Beaumont J, editors. Hemisphere Function in the Human Brain. London: Elek Science; 1974.

45. Oldfield RC. The assessment and analysis of handedness: the Edinburgh inventory. Neuropsychologia. 1971;9:97-113.

46. Moher D, Liberati A, Tetzlaff J, Altman DG, Prisma Group. Preferred reporting items for systematic reviews and meta-analyses: the PRISMA statement. PLoS Med. 2009;6:e1000097.

47. Page MJ, McKenzie J, Bossuyt P, Boutron I, Hoffmann T, Mulrow cd, ... Moher D. The PRISMA 2020 statement: an updated guideline for reporting systematic reviews 2020, September 14. doi:https://doi.org/10. 31222/osf.io/v7gm2.

48. Dragović M, Hammond G. Handedness in schizophrenia: a quantitative review of evidence. Acta Psychiatr Scand. 2005;111:410-9. https://doi. org/10.1111/j.1600-0447.2005.00519.x.

49. Hirnstein M, Hugdahl K. Excess of non-right-handedness in schizophrenia: meta-analysis of gender effects and potential biases in handedness assessment. Br J Psychiat. 2014;205:260-7. https://doi.org/10.1192/bjp. bp.113.137349.

50. Sommer IE, Ramsey N, Kahn RS, Aleman A, Bouma A. Handedness, language lateralisation and anatomical asymmetry in schizophrenia: 
meta-analysis. Br J Psychiat. 2001;178:344-51. https://doi.org/10.1192/ bjp.178.4.344.

51. Noga JT, Vladar K, Torrey EF. A volumetric magnetic resonance imaging study of monozygotic twins discordant for bipolar disorder. Psychiat Res Neuroimag. 2001;106:25-34. https://doi.org/10.1016/s09254927(00)00084-6.

52. Hegarty JP, Lazzeroni LC, Raman MM, Pegoraro LFL, Monterrey JC, Cleveland SC, et al. Genetic and environmental influences on lobar brain structures in twins with autism. Cereb Cortex. 2020;30:1946-56. https://doi.org/10.1093/cercor/bhz215

53. Spaniel F, Herynek V, Hajek T, Dezortova M, Horacek J, Hajek M, et al. Magnetic resonance relaxometry in monozygotic twins discordant and concordant for schizophrenia. Eur Psychiatry. 2005;20:41-4. https://doi. org/10.1016/j.eurpsy.2004.11.004.

54. Sharma A, Sauer H, Smit DJA, Bender S, Weisbrod M. Genetic liability to schizophrenia measured by p300 in concordant and discordant monozygotic twins. Psychopathology. 2011;44:398-406. https://doi. org/10.1159/000325883.

55. Bishop DVM, Bates TC. Heritability of language laterality assessed by functional transcranial Doppler ultrasound: a twin study. Wellcome Open Res. 2019;4:161. https://doi.org/10.12688/wellcomeopenres. 15524.2.

56. *Wilson AC, Bishop DVM. Resounding failure to replicate links between developmental language disorder and cerebral lateralisation. PeerJ. 2018;6: e4217. https://doi.org/10.7717/peerj.4217.

57. Bishop DVM. Handedness and specific language impairment: a study of 6-year-old twins. Dev Psychobiol. 2005;46:362-9. https://doi.org/10. 1002/dev.20062.

58. Miskowiak KW, Svendsen AMB, Harmer CJ, Elliott R, Macoveanu J, Siebner $H R$, et al. Differences in neural and cognitive response to emotional faces in middle-aged dizygotic twins at familial risk of depression. Psychol Med. 2017;47:2345-57. https://doi.org/10.1017/S003329171 7000861.

59. *Bouterwek H. Rechts-links Abwandlung in Handigkeit and seelischer Artung. Zeitschrift fuer menschliche Vererbungs- und Konstitutionslehre. 1938;21:737-60.

60. *Perelle IB, Ehrman L. An international study of human handedness: the data. Behav Genet. 1994;24:217-27. https://doi.org/10.1007/BF010 67189.

61. *Shields J. Monozygotic twins: Brought up apart and brought up together. London: Oxford University Press; 1962.

62. *Liebing M. Zur Verteilung der handigkeit bei Vorschulkindern. Arztl Jugendkd. 1986;77:319-23.

63. Segal NL. Revisiting sources of left-handedness in multiple-birth individuals. Proc Natl Acad Sci U S A. 2018;115:5832-4. https://doi.org/10. 1073/pnas.1806879115.

64. Ahrenfeldt LJ, Christensen K, Segal NL, Hur Y-M. Opposite-sex and same-sex twin studies of physiological, cognitive and behavioral traits. Neurosci Biobehav Rev. 2020;108:322-40. https://doi.org/10.1016/j. neubiorev.2019.11.004.

65. Segal NL. Twins, birth weight, cognition, and handedness. Proc Natl Acad Sci U S A. 2012. https://doi.org/10.1073/pnas.1213701109.

66. Gopalakrishman. Perinatal Factors and Umbilical Cord Characteristics in Determining Handedness: Results from the Belgian East Flanders Prospective Twin Survey. Doctoral dissertation, University of Birmingham. 2012

67. *Hulshoff Pol HE, Schnack HG, Posthuma D, Mandl RCW, Baaré WF, van Oel $\mathrm{C}$, et al. Genetic contributions to human brain morphology and intelligence. J Neurosci. 2006;26:10235-42. https://doi.org/10.1523/ JNEUROSCI.1312-06.2006.

68. Bootsman F. Brain structure in bipolar disorder: A longitudinal neuroimaging study in twins: (Doctoral dissertation, Utrecht University); 2016.

69. *Vuoksimaa E, Koskenvuo M, Rose RJ, Kaprio J. Origins of handedness: a nationwide study of 30,161 adults. Neuropsychologia. 2009;47:1294301. https://doi.org/10.1016/j.neuropsychologia.2009.01.007.

70. Cannon TD, Huttunen MO, Lönnqvist J, Tuulio-Henriksson A, Pirkola T, Glahn DC, et al. The inheritance of neuropsychological dysfunction in twins discordant for schizophrenia. Am J Hum Genet. 2000;67:369-82. https://doi.org/10.1086/303006.

71. Karlsgodt KH, Glahn DC, van Erp TGM, Therman S, Huttunen MO, Manninen $\mathrm{M}$, et al. The relationship between performance and fMRI signal during working memory in patients with schizophrenia, unaffected co-twins, and control subjects. Schizophr Res. 2007;89:191-7. https:// doi.org/10.1016/j.schres.2006.08.016.

72. Pirkola T, Tuulio-Henriksson A, Glahn DC, Kieseppä T, Haukka J, Kaprio $J$, et al. Spatial working memory function in twins with schizophrenia and bipolar disorder. Biol Psychiatry. 2005;58:930-6. https://doi.org/10. 1016/j.biopsych.2005.05.041.

73. Bachman P, Kim J, Yee CM, Therman S, Manninen M, Lönnqvist J, et al. Efficiency of working memory encoding in twins discordant for schizophrenia. Psychiatry Res. 2009;174:97-104. https://doi.org/10.1016/j. pscychresns.2009.04.010.

74. Kieseppä T, van Erp TGM, Haukka J, Partonen T, Cannon TD, Poutanen $V-P$, et al. Reduced left hemispheric white matter volume in twins with bipolar I disorder. Biol Psychiatry. 2003;54:896-905. https://doi.org/10. 1016/S0006-3223(03)00373-1.

75. Kieseppä T, Tuulio-Henriksson A, Haukka J, van Erp TGM, Glahn DC, Cannon TD, et al. Memory and verbal learning functions in twins with bipolar-l disorder, and the role of information-processing speed. Psychol Med. 2005;35:205-15.

76. Fortin M, Yuan Y, Battié MC. Factors associated with paraspinal muscle asymmetry in size and composition in a general population sample of men. Phys Ther. 2013;93:1540-50. https://doi.org/10.2522/ptj.20130051.

77. *Heikkilä K, Vuoksimaa E, Saari-Kemppainen A, Kaprio J, Rose RJ, Haukka $\mathrm{J}$, et al. Higher prevalence of left-handedness in twins? Not after controlling birth time confounders. Twin Res Hum Genet. 2015;18:526-32. https://doi.org/10.1017/thg.2015.53.

78. Heikkilä K. In search of perinatal correlates of left-handedness. 2020.

79. Medland SE, Duffy DL, Spurdle AB, Wright MJ, Geffen GM, Montgomery GW, Martin NG. Opposite effects of androgen receptor CAG repeat length on increased risk of left-handedness in males and females. Behav Genet. 2005:35:735-44. https://doi.org/10.1007/ s10519-005-6187-3.

80. Kanchibhotla SC, Mather KA, Thalamuthu A, Zhuang L, Schofield PR, Kwok JBJ, et al. Genetics of microstructure of the corpus callosum in older adults. PLoS ONE. 2014;9: e113181. https://doi.org/10.1371/journ al.pone.0113181.

81. *Dooland KV, Townsend GC, Kaidonis JA. Prevalence and side preference for tooth grinding in twins. Aust Dent J. 2006;51:219-24.

82. *Basso O, Olsen J, Holm NV, Skytthe A, Vaupel JW, Christensen K. Handedness and mortality: a follow-up study of Danish twins born between 1900 and 1910. Epidemiology (Cambridge, Mass). 2000;11:576-80. https://doi.org/10.1097/00001648-200009000-00014.

83. *Dechaume MP. Contribution a l'étude de la dominance laterale chez les jumeaux. As cited by Sicotte et al.: Unpublished; 1999. p. 1957.

84. *Thyss J. Etude bibliographique et critique du problème des gauchers. Unpublished: As cited by Sicotte et al., 1999; 1946

85. *Hirsch NDM. Twins, heredity and environment. Cambridge, MA: Harvard University Press; 1930.

86. *Koch HL. Twins and twin relations. Chicago: University of Chicago Press; 1966.

87. Viechtbauer W. Conducting meta-analyses in R with the metafor package. J Stat Soft. 2010;36:1-48. https://doi.org/10.18637/jss.v036.103.

88. *Shimizu A, Endo M. Comparison of patterns of handedness between twins and singletons in Japan. Cortex. 1983;19:345-52. https://doi.org/ 10.1016/s0010-9452(83)80005-7.

89. Higgins JPT, Thompson SG, Deeks JJ, Altman DG. Measuring inconsistency in meta-analyses. BMJ. 2003;327:557-60. https://doi.org/10.1136/ bmj.327.7414.557.

90. Duval S, Tweedie R. Trim and fill: a simple funnel-plot-based method of testing and adjusting for publication bias in meta-analysis. Biometrics. 2000;56:455-63. https://doi.org/10.1111/j.0006-341x.2000.00455.x.

91. ${ }^{*}$ Carlier M, Spitz E, Vacher-Lavenu MC, Villéger P, Martin B, Michel F. Manual performance and laterality in twins of known chorion type. Behav Genet. 1996;26:409-17. https://doi.org/10.1007/BF02359485.

92. Law A, McCoy M, Lynen R, Curkendall SM, Gatwood J, Juneau PL, Landsman-Blumberg P. The prevalence of complications and healthcare costs during pregnancy. J Med Econ. 2015;18:533-41. https://doi.org/ 10.3111/13696998.2015.1016229.

93. MacDorman MF, Singh GK. Midwifery care, social and medical risk factors, and birth outcomes in the USA. J Epidemiol Community Health. 1998;52:310-7. https://doi.org/10.1136/jech.52.5.310. 
94. Lee-Feldstein A, Harburg E. Alcohol use among right-and left-handed persons in a small community. J Stud Alcohol. 1982;43:824-9.

95. Gilbert AN, Wysocki CJ. Hand preference and age in the United States. Neuropsychologia. 1992;30:601-8.

96. Schachter SC, Ransil BJ, Geschwind N. Associations of handedness with hair color and learning disabilities. Neuropsychologia. 1987;25:269-76.

97. McManus IC. Genetics of handedness in relation to language disorder. Neurology. 1984;42:125-38.

98. Klöppel S, Mangin J-F, Vongerichten A, Frackowiak RSJ, Siebner HR Nurture versus nature: long-term impact of forced right-handedness on structure of pericentral cortex and basal ganglia. J Neurosci. 2010;30:3271-5. https://doi.org/10.1523/JNEUROSCI.4394-09.2010.

99. Fagard J, Chapelain A, Bonnet P. How should "ambidexterity" be estimated? Laterality. 2015;20:543-70.

100. Newman HH. Studies of human twins: II. Asymmetry reversal, of mirror imaging in identical twins. Biol Bull. 1928;55:298-315.

101. *Stocks P. A biometric investigation of twins and their brothers and sisters. Ann Eugen. 1933;5:1-55.

102. *Komai T, Fukuoka G. A note on the problem of mirror-imaging in human twins. Hum Biol. 1934;6:24-32.

103. Davis JO, Phelps JA. Twins with schizophrenia: genes or germs? Schizophr Bull. 1995;21:13-8.

104. Davis JO, Phelps JA, Bracha HS. Prenatal development of monozygotic twins and concordance for schizophrenia. Schizophr Bull. 1995;21:357-66.

105. Borod JC, Herbert SC, Koff E. Left-handers and right-handers compared on performance and preference measures of lateral dominance. $\mathrm{Br}$ J Psychol. 1984;74:177-86.

106. Todor JL, Doane T. Handedness classification: preference versus proficiency. Percept Mot Skills. 1977;45:1041-2.

107. Triggs WJ, Calvanio R, Levine M, Heaton RK, Heilman KM. Predicting hand preference with performance on motor tasks. Cortex. 2000;36:679-89.

108. Buenaventura Castillo C, Lynch AG, Paracchini S. Different laterality indexes are poorly correlated with one another but consistently show the tendency of males and females to be more left- and right-lateralized, respectively. R Soc Open Sci. 2020;7: 191700. https://doi.org/10. 1098/rsos.191700.

109. Corey DM, Hurley MM, Foundas AL. Right and left handedness defined: a multivariate approach using hand preference and hand performance measures. Neuropsychiat Neuropsychol Behav Neurol. 2001;14:144-52.

110. McDowell A, Felton A, Vazquez D, Chiarello C. Neurostructural correlates of consistent and weak handedness. Laterality. 2016;21:348-70. https:// doi.org/10.1080/1357650X.2015.1096939.

111. Christman SD, Prichard EC. Half oaks, half willows: Degree, not direction, of handedness underlies both stable prevalence in the human population and speciesbeneficial variations in cognitive flexibility. Evol Psychol Sci. 2016;2:228-36.

112. Prichard EC, Propper RE, Christman SD. Degree of handedness, but not direction, is a systematic predictor of cognitive performance. Front Psychol. 2013;4:9. https://doi.org/10.3389/fpsyg.2013.00009.

113. Arning L, Ocklenburg S, Schulz S, Ness V, Gerding WM, Hengstler JG, et al. PCSK6 VNTR polymorphism is associated with degree of handedness but not direction of handedness. PLoS ONE. 2013;8: e67251. https://doi.org/10.1371/journal.pone.0067251.

114. Brandler WM, Morris AP, Evans DM, Scerri TS, Kemp JP, Timpson NJ, et al. Common variants in left/right asymmetry genes and pathways are associated with relative hand skill. PLoS Genet. 2013;9: e1003751. https://doi.org/10.1371/journal.pgen.1003751.

115. *Boklage CE. On the distribution of nonrighthandedness among twins and their families. Acta Genet Med Gemellol (Roma). 1981;30:167-87. https://doi.org/10.1017/s0001566000007649.

116. ${ }^{*}$ Carter-Saltzman L, Scarr-Salapatek S, Barker WB, Katz S. Left-handedness in twins: incidence and patterns of performance in an adolescent sample. Behav Genet. 1976;6:189-203. https://doi.org/10.1007/BF010 67148.

117. ${ }^{*}$ Coren S. Twinning is associated with an increased risk of left-handedness and inverted writing hand posture. Early Hum Dev. 1994;40:23-7. https://doi.org/10.1016/0378-3782(94)90096-5.

118. ${ }^{*}$ Dahlberg G. Twin births and twins from a hereditary point of view. Stockholm: Tidens forlag; 1926.
119. *Derom C, Thiery E, Vlietinck R, Loos RJF, Derom R. Handedness in twins according to zygosity and chorion type: a preliminary report. Behav Genet. 1996;26:407-8. https://doi.org/10.1007/BF02359484.

120. *Forrai G, Bánkövi G. A Hungarian twin study on hand clasping, arm folding and tongue curling. Acta Biol Hung. 1983;34:99-106.

121. *Hay DA, Howie PM. Handedness and differences in birthweight of twins. Percept Mot Skills. 1980;51:666. https://doi.org/10.2466/pms. 1980.51.2.666.

122. *Loehlin JC, Nichols RC. Heredity, environment and personality: a study of 850 sets of twins. Austin: University of Texas Press; 1976.

123. *McManus IC. Handedness, language dominance and aphasia: a genetic model. Psychol Med Monogr Suppl. 1985;8:1-40.

124. *Morley R, Caffrey EA. Handedness in blood donors: no association with blood group or twinning. Cortex. 1994;30:707-10. https://doi.org/10. 1016/S0010-9452(13)80247-X

125. *Neale MC. Handedness in a sample of volunteer twins. Behav Genet. 1988;18:69-79. https://doi.org/10.1007/BF01067076.

126. *Newman HH, Freeman FN, Holzinger KJ. Twins: a study of heredity and environment. Chicago: University of Chicago Press; 1937.

127. *Orlebeke JF, Knol DL, Koopmans JR, Boomsma DI, Bleker OP. Lefthandedness in twins: genes or environment? Cortex. 1996;32:479-90. https://doi.org/10.1016/s0010-9452(96)80005-0.

128. * Osborne RT. Twins: black and white. Athens: Foundation for Human Understanding; 1980.

129. *Rife DE. An application of gene frequency analysis to the interpretation of data from twins. Hum Biol. 1950;22:136-45.

130. *Siemens HW. Uber Linkshandigkeit. Virchow's archives. 1924:252.

131. *Springer SP, Searleman A. Laterality in twins: the relationship between handedness and hemispheric asymmetry for speech. Behav Genet. 1978;8:349-57. https://doi.org/10.1007/BF01067398.

132. *von Verschuer O. Die vererbungsbiologische Zwillingsforschung. In: Kraus F, editor. Ergebnisse der Inneren Medizin und Kinderheilkunde. Berlin Heidelberg: Springer Verlag; 1927.

133. *Wilson PT, Jones HE. Left-handedness in twins. Genetics. 1932;17:560-71.

134. *Armour JAL, Davison A, McManus IC. Genome-wide association study of handedness excludes simple genetic models. Heredity (Edinb). 2014;112:221-5. https://doi.org/10.1038/hdy.2013.93.

135. *Bohlken MM, Mandl RCW, Brouwer RM, van den Heuvel MP, Hedman AM, Kahn RS, Hulshoff Pol HE. Heritability of structural brain network topology: a DTI study of 156 twins. Hum Brain Mapp. 2014;35:5295-305. https://doi.org/10.1002/hbm.22550

136. *Dragović M, Milenković S, Kocijancić D, Zlatko S. Etiological aspect of left-handedness in adolescents. Srp Arh Celok Lek. 2013;141:354-8. https://doi.org/10.2298/sarh1306354d.

137. *Eckert MA, Leonard CM, Molloy EA, Blumenthal JD, Zijdenbos A, Giedd $\mathrm{JN}$. The epigenesis of planum temporale asymmetry in twins. Cereb Cortex. 2002;12:749-55. https://doi.org/10.1093/cercor/12.7.749.

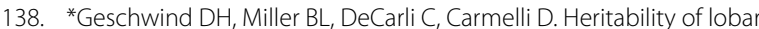
brain volumes in twins supports genetic models of cerebral laterality and handedness. Proc Natl Acad Sci U S A. 2002;99:3176-81. https://doi. org/10.1073/pnas.052494999.

139. *Karim KJ, Mustafa SK, Ahmad KK. Human lateralization among monozygotic and dizygotic twins in Koya town. JBLS. 2014;6:139. https://doi.org/10.5296/jbls.v6i1.6776.

140. ${ }^{*}$ Ooki S. Genetic and environmental influences on the handedness and footedness in Japanese twin children. Twin Res Hum Genet. 2005;8:649-56. https://doi.org/10.1375/twin.8.6.649.

141. *Ordaz SJ, Lenroot RK, Wallace GL, Clasen LS, Blumenthal JD, Schmitt JE, Giedd JN. Are there differences in brain morphometry between twins and unrelated singletons? A pediatric MRI study. Genes Brain Behav. 2010;9:288-95. https://doi.org/10.1111/j.1601-183X.2009.00558.x.

142. ${ }^{*}$ Raznahan A, Greenstein D, Lee NR, Clasen LS, Giedd JN. Reply to Segal: Are relationships between birth weight and intelligence quotient variation within twin pairs modulated by patterns of handedness discordance? Proc Natl Acad Sci U S A. 2012;109:E3294-E3294. https://doi.org/ 10.1073/pnas.1214891109.

143. *Reiss M, Tymnik G, Kögler P, Kögler W, Reiss G. Laterality of hand, foot, eye, and ear in twins. Laterality. 1999;4:287-97. https://doi.org/10.1080/ 713754337. 
144. *Ross DC, Jaffe J, Collins RL, Page W, Robinette D. Handedness in the NAS/NRC twin study. Laterality. 1999;4:257-64. https://doi.org/10.1080/ 713754342.

145. *Segal NL. Co-conspirators and double-dealers: a twin film analysis. Personality Individ Differ. 2002;33:621-31. https://doi.org/10.1016/ S0191-8869(01)00176-3.

146. * ${ }^{*}$ Suzuki K, Ando J. Genetic and environmental structure of individual differences in hand, foot, and ear preferences: a twin study. Laterality. 2014. https://doi.org/10.1080/1357650X.2013.790396.

147. * ${ }^{*}$ Suzuki K, Ando J, Satou N. Genetic effects on infant handedness under spatial constraint conditions. Dev Psychobiol. 2009;51:605-15. https:// doi.org/10.1002/dev.20395.

148. *Yoon U, Fahim C, Perusse D, Evans AC. Lateralized genetic and environmental influences on human brain morphology of 8-year-old twins. Neuroimage. 2010;53:1117-25. https://doi.org/10.1016/j.neuroimage. 2010.01.007.

\section{Publisher's Note}

Springer Nature remains neutral with regard to jurisdictional claims in published maps and institutional affiliations.

- fast, convenient online submission

- thorough peer review by experienced researchers in your field

- rapid publication on acceptance

- support for research data, including large and complex data types

- gold Open Access which fosters wider collaboration and increased citations

- maximum visibility for your research: over $100 \mathrm{M}$ website views per year

At $\mathrm{BMC}$, research is always in progress.

Learn more biomedcentral.com/submissions 